\title{
Cumulative Damage Evaluation of RC Bridge Piers subjected to Multiple Earthquakes
}

\author{
Do Hyung Lee, ${ }^{1}$ Byeong Hwa Kim, ${ }^{2}$ Jung Joong Kim, ${ }^{2}$ and WooSeok Kim ${ }^{3}$ \\ ${ }^{1}$ Department of Civil, Railroad and Unmanned Systems Engineering, PaiChai University, Daejeon 35345, Republic of Korea \\ ${ }^{2}$ Department of Civil Engineering, Kyungnam University, Gyeongnam 51767, Republic of Korea \\ ${ }^{3}$ Department of Civil Engineering, Chungnam University, Daejeon 34134, Republic of Korea
}

Correspondence should be addressed to WooSeok Kim; wooseok@cnu.ac.kr

Received 27 December 2019; Revised 30 June 2020; Accepted 13 July 2020; Published 7 August 2020

Academic Editor: Zhixiong Li

Copyright ( 92020 Do Hyung Lee et al. This is an open access article distributed under the Creative Commons Attribution License, which permits unrestricted use, distribution, and reproduction in any medium, provided the original work is properly cited.

Successive earthquakes of Kocaeli and Duzce within three months indicated that even the survived lifeline structures such as bridges under the former event may have damage or collapse potential under the latter event due to their possible stiffness degradation. It is thus important that a rigorous seismic analysis of such structures should account for the effect of prior earthquake damage. For this purpose, nonlinear seismic analysis of a reinforced concrete bridge structure has been carried out under both single and multiple earthquake ground motions. Behavior and response evaluation of the bridge piers subjected to such motions have been discussed in terms of using both flexure-axial and flexure-shear-axial interaction models. Analytical results show that the stiffness degradation under multiple earthquake ground motions is more pronounced than that under single earthquake ground motion. In addition, comparison of the response without and with shear demonstrates that shear deformation is of significance. The response with shear exhibits the increase in displacement demand and decrease in lateral force carrying capacity, leading to a decrease in energy dissipation capacity. It is concluded that seismic analysis of reinforced concrete bridge structure should account for the effect of multiple earthquake ground motions to assess the demand on such structure properly.

\section{Introduction}

Most of the progress in earthquake-resistant design has been achieved in terms of the observation of damage inflicted by earthquakes. The perception of the way in which bridge responds to an earthquake was dramatically changed by the damage observed after the 1971 San Fernando earthquake. Bridge damage induced by that earthquake clearly demonstrated that the seismic design provisions at that time were inadequate [1]. Subsequent to the San Fernando earthquake, much research effort has been dedicated to improve the seismic resistance of bridges. Although significant advances have been achieved, bridges, in particular those constructed from reinforced concrete, have not performed as expected.

Whereas most of the damage analyses for such structures have been conducted in terms of the single ground motion of all components, a few studies have been reported in the literature regarding the seismic response analyses of such structures subjected to multiple earthquake ground motions.

The earthquake of Kocaeli on 17 August 1999 caused severe damage to many reinforced concrete structures [2]. Following the event (three months later), on the evening of 12 November 1999, another earthquake stroke the area of Duzce and Bolu in the northwestern part of Turkey, which is a nearby region of Kocaeli (Izmit) [3]. This implies that the survived lifeline structures such as bridges under the former event may have damage or collapse potential under the latter event due to their possible stiffness degradation. Therefore, it is important that a rigorous seismic analysis of such structures should account for the effect of multiple earthquake ground motions. Work by Aschheim and Black [4] was among those a few studies that took into account the effect of prior earthquake damage. However, this study was limited since the prior damage was modeled as an assumed reduction in initial stiffness. 
Studies considering repeated sequence effects were conducted in terms of using single-degree-of-freedom systems [5, 6]. Recently, Hatzigeorgiou and Beskos [7] developed a methodology for the quantification of the seismic sequence effect directly onto displacement demands. After a year later, Hatzigeorgiou [8] proposed a new procedure for the ductility control of single-degree-of-freedom systems under repeated near-fault earthquakes. Subsequently, elastic and inelastic spectra were computed for various viscous damping ratios, postyield stiffness ratios, and ductility levels. Yaghmaaeri-Sabegh and Ruiz-Garcia [9] also investigated the ground motion effects of the Varzaghan-Ahar accelerogram sequences recorded during Iran earthquake of 2012 on the nonlinear response of elastic-perfectly plastic singledegree-of-freedom systems.

In addition, multiple earthquake effect was also carried out for reinforced concrete and steel structures. Fragiacomo et al. [10] investigated the damage accumulation produced on multi-degree-of-freedom steel frames by repeated earthquakes, and they compared responses between multidegree-of-freedom and equivalent single-degree-of-freedom systems. Li and Ellingwood [11] evaluated the potentials for aftershocks to cause additional damage to steel moment frame buildings and provided a probabilistic description of structural damage states prior to and following the aftershocks. Ruiz-Garcia and Negrete-Manriquez [12] conducted an analytical study aiming at providing an understanding on the influence of aftershocks on drift demands in regular existing moment-resisting frame buildings. Sarno [13] investigated the effects of multiple earthquakes on reinforced concrete structures. Comprehensive parametric response spectra were evaluated with degrading (stiffness and/or strength) and nondegrading hysteretic models to account for the response of reinforced concrete structures. Raghunandan and Liel [14] quantified the influence of ground motion duration on the predicted collapse response of concrete frame structures. Incremental dynamic analysis was carried out on a set of archetypical reinforced concrete buildings subjected to various ground motions with varying duration. Abdelnaby and Elnashai [15] conducted an assessment of reinforced concrete frames subjected to repeated strong motions in terms of using numerical models that capture the degrading behavior of reinforced concrete frame. Hosseinpour and Abdelnaby [16] also investigated the effects of repeated shaking on the behavior of two eightstory reinforced concrete buildings (both regular and irregular in height) prone to multiple earthquakes.

However, most of the previous studies considering repeated earthquakes are related to single-degree-of-freedom systems and building structures, and very few studies are conducted for reinforced concrete bridge structures. This situation has motivated the present work; the main objective of which is to investigate the effects of multiple earthquake ground motions on the stiffness degradation of reinforced concrete bridges, particularly piers.

In addition, axial forces on bridge piers may vary during earthquake excitations due to vertical ground motion. Vertical ground motion components combined with horizontal components may significantly affect the axial force variation [17]. In particular, taking into account that bridge piers are in general subjected to a high level of axial force due to the weight of the superstructure, the axial force variation can be of significance for such members. Although the axial force variation during earthquake excitations is qualitatively acknowledged, only a few studies include the varying axial force effects on reinforced concrete frame structures [18-20].

Galal and Ghobarah [21] suggested an element for the modeling of the biaxial flexural and shear behavior of reinforced concrete columns subjected to various levels of axial forces. Prakash et al. [22] conducted experimental work on reinforced concrete circular columns under various levels of combined cyclic bending, shear, and torsion, together with finite element analyses. However, these studies are somewhat limited to simulate the response of such columns subjected to continually varying axial forces. In addition, Setzler and Sezen [23] developed a model that can predict the monotonic lateral force-displacement relationship for reinforced concrete columns subjected to lateral loading. Subsequently, Sezen and Chowdhury [24] also proposed a macromodel to simulate the cyclic lateral load-deformation response of reinforced concrete columns. Cyclic responses corresponding to flexural, longitudinal bar slip and shear deformations were calculated using the model. However, those models do not likely seem to simulate the interactive behaviour of flexure-shear-axial force variation.

In line with the above, cumulative earthquake damage due to multiple earthquakes was investigated on a reinforced concrete bridge structure. For this purpose, nonlinear inelastic response analysis of a reinforced concrete bridge was carried out under both single and multiple earthquake ground motions. In addition, hysteretic shear-axial interaction representation was employed to simulate flexureshear-axial interaction. Subsequently, behavior and response with and without shear for reinforced concrete bridge piers are discussed.

\section{Analysis Program and Shear Representation}

2.1. Analysis Program ZeusNL. ZeusNL [25] has been developed for the nonlinear inelastic analysis of two- and three-dimensional steel, reinforced concrete, and composite structures under static and dynamic loading, taking into account the effects of both geometric and material nonlinearities. ZeusNL [25] provides a series of solution strategies for nonlinear analysis as described below.

In static analysis, both force and displacement loading can be applied with independent values or constrained to vary in proportional ratios. In addition, displacement and acceleration time histories can be applied at the supports. Also availed of is static adaptive strategy where the applied load pattern is varying through the different steps of the procedure. This allows the stiffness degradation and the period elongation of the structures to be accurately described. The solution procedure can be full or modified Newton-Raphson method. Automatic load-step reduction is employed to provide an optimum efficiency, and convergence criteria can be defined in terms of either displacement or force. 


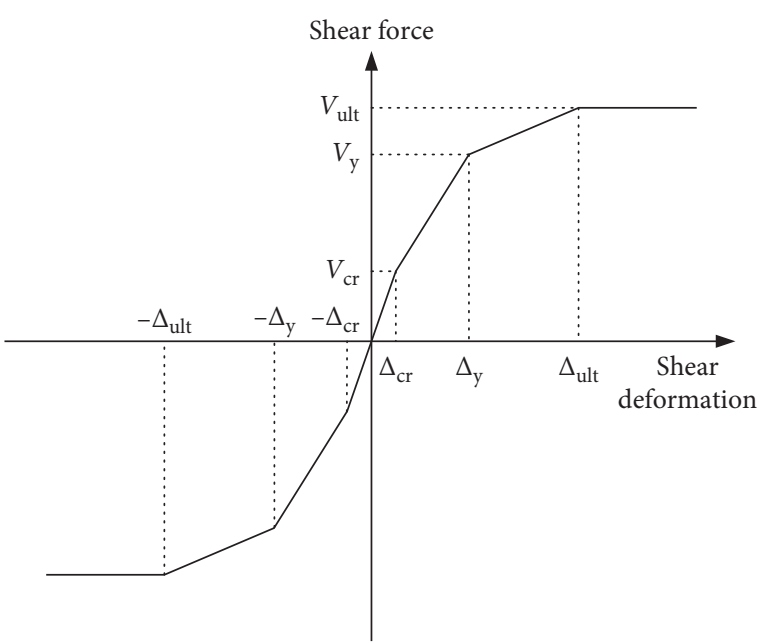

(a)

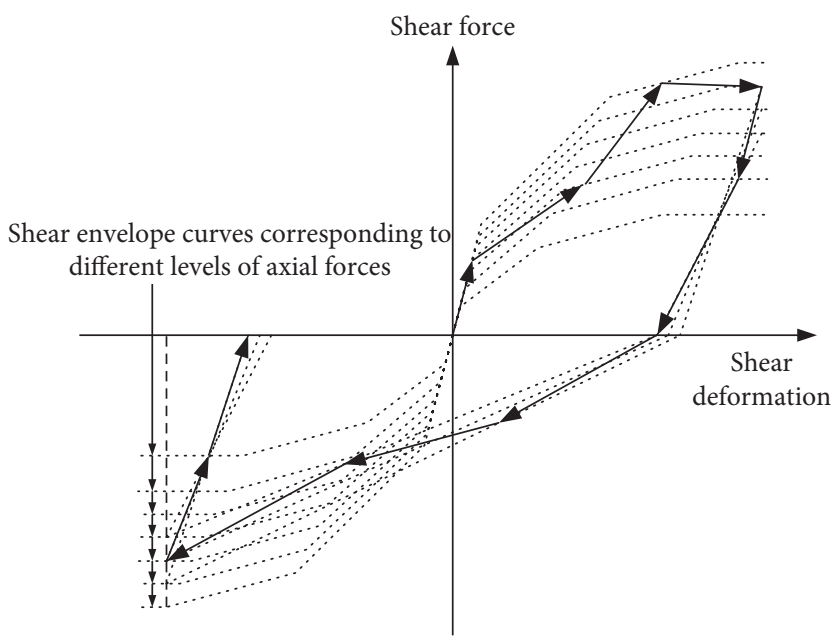

(b)

Figure 1: Hysteretic shear-axial interaction representation. (a) Quatrilinear symmetric envelope curve. (b) Shear stiffness transitions due to axial force variation.

For dynamic analysis, the Lanczos algorithm is used for eigenvalue analysis to obtain the required natural frequencies and mode shapes. Time-history analysis is performed through numerically integrating the equation of motion using either the unconditionally stable Newmark family of algorithm or the Hilber-Hughes-Taylor algorithm [26] within automatic time-step adjustment during analysis. Equilibrium is ensured for each time step using the same iterative strategies as employed in static analysis.

A variety of cross section types are available including steel rectangular solid, hollow, and I-sections, reinforced concrete columns (rectangular and circular) and T-beam sections, and both fully and partially encased composite sections over which a number of monitoring areas are divided, in order to account accurately for the inelastic response of structural members. The layout of steel and both confined and unconfined concrete within the cross section can then be modeled, with the computation of stress resultants being performed automatically.

A detailed description of all available elements and material models in ZeusNL [25] and validations can be found in references [25, 27-32].

2.2. Hysteretic Shear Representation. Inelastic deformations generated during seismic response are not limited to flexural deformation. Saatciouglu and Ozcebe [33] indicated from reinforced concrete column tests that inelastic shear deformation can significantly affect total deformation in local areas. Moreover, a greater shear capacity in comparison with that corresponding to flexural capacity does not always ensure elastic shear behavior. Therefore, there is a need for a simple yet accurate model for predicting the flexure and shear interactive behavior of reinforced concrete columns, combined with axial force variation.

In view of the above, the hysteretic shear models for variable axial forces were developed and implemented in ZeusNL [25]. The new formulations were composed of two parts, the envelope curve and a set of hysteresis rules. The envelope curve is derived from the modified compression field theory (referred to as MCFT [34] hereafter). The MCFT [34] was widely used for the analysis of reinforced concrete members and gave a good correlation ([35] amongst many others). However, the stress-strain relationship for concrete in compression used in the MCFT does not seem to provide an effective confinement to the core concrete confined with circular hoops or spirals. Thus, the stress-strain relationship for concrete in compression is modified to consider the confinement effect [36]. The envelope curve is represented by a quatrilinear symmetric curve as shown in Figure 1(a) which accounts for the cracking, yielding, and ultimate states denoted by "cr," "y," and "ult," respectively. The cracking force is defined as the force at which the principal tensile stress is equal to $0.33 \sqrt{f_{c o}}\left(f_{c o}\right.$ is a maximum stress of concrete), and yield force is defined as the point obtained by extrapolating a straight line from the origin through 0.75 of the ultimate force to meet the horizontal line passing through the ultimate force.

To describe the inelastic hysteretic shear response, a set of hysteresis rules proposed by Ozcebe and Saatcioglu [37] was adopted for the evaluation of loading and unloading (total and partial). However, since most of the expressions derived in the development of the hysteretic shear model were based on the limited experimental data, direct use of the model in inelastic time-history analysis was uncertain. Thus, modifications and developments were made with regard to the hysteresis rules [38]. Primary developments are the relationship between axial force and its effect on pinching for various levels of axial forces, and formulation between the number of cycles at a constant level of deformation and its effect on stiffness degradation. Detailed description can be found in references [36, 38].

Based on the envelope and a set of shear hysteresis rules, hysteretic shear-axial interaction representation was developed. The basic concept in including the effect of varying axial forces is that the stiffness in the current time step is 

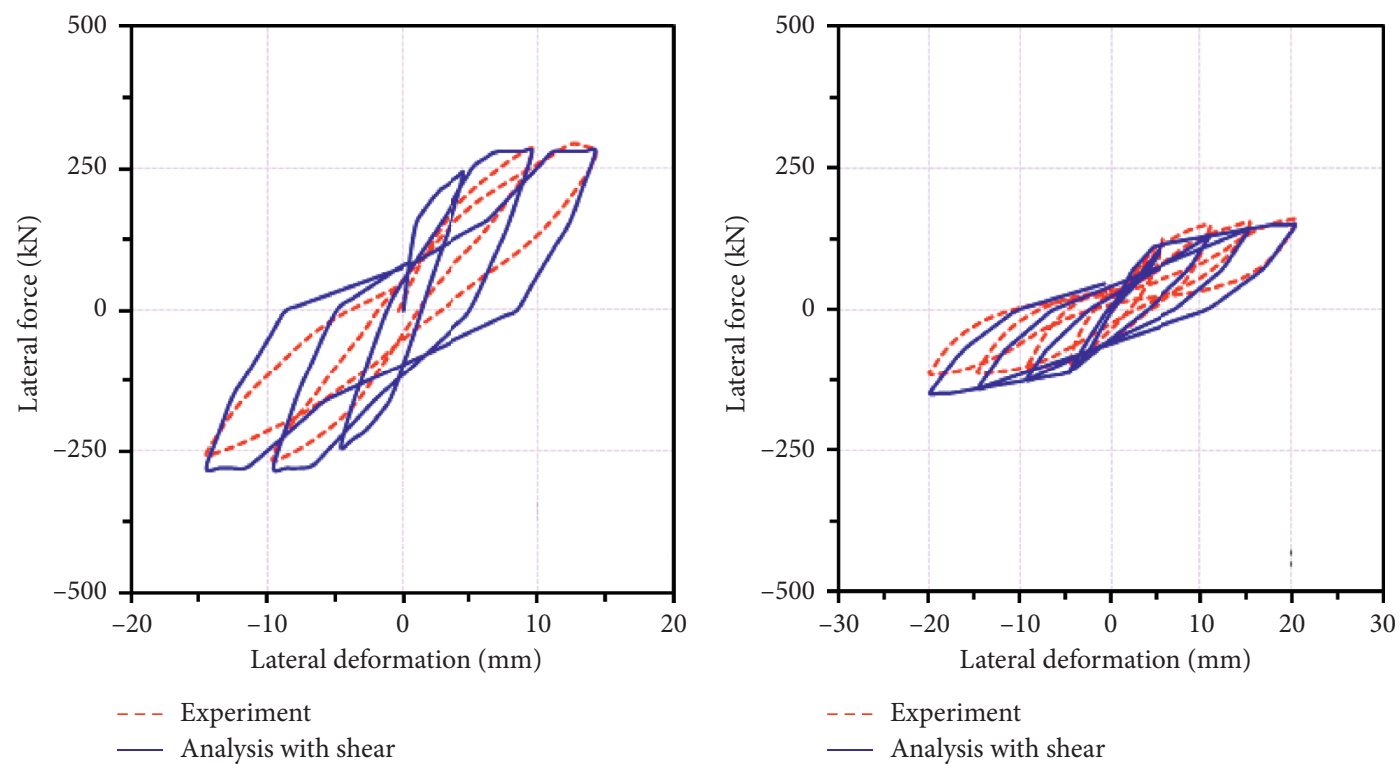

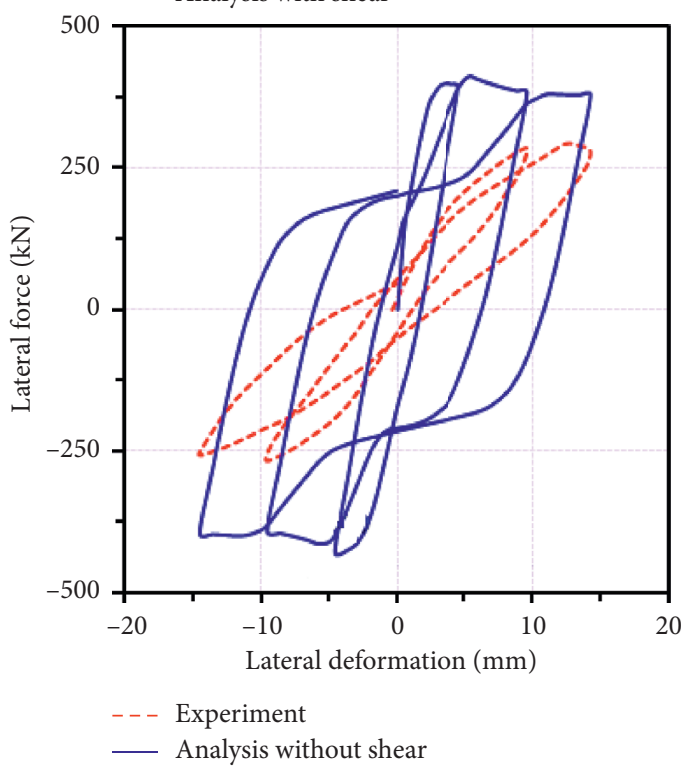

(a)

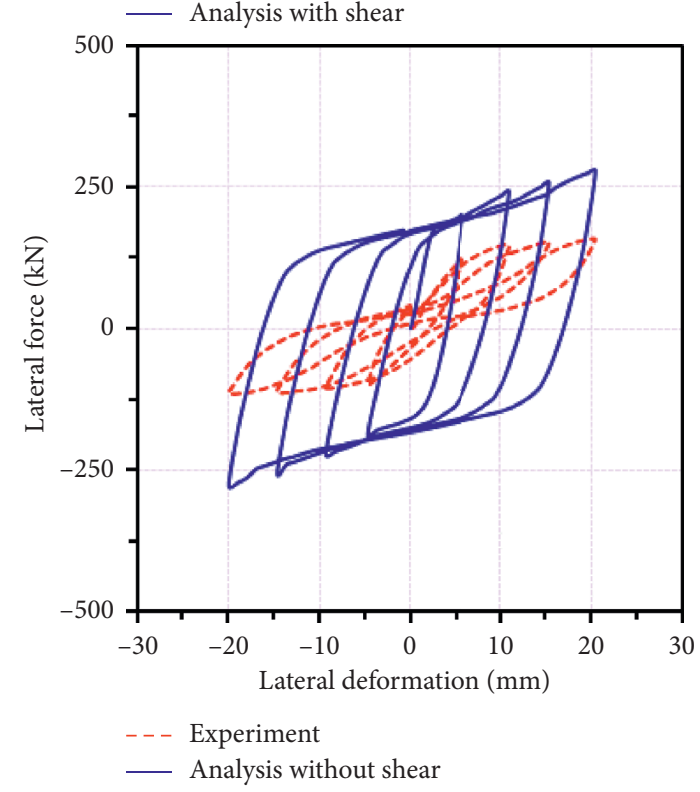

(b)

Figure 2: Representative validation of hysteretic shear representation [39]. (a) Specimen 120C-U. (b) Specimen 100T-U.

calculated by introducing appropriate shifts corresponding to the current level of axial force between series of envelope curves derived for constant levels of axial force. This is an equivalent stepwise linear approach. These transitions represent either hardening (increase in stiffness) or softening (decrease in stiffness) of the member due to variation of axial force. Cracking, yielding, and ultimate levels are also shifted in accordance with the axial force variation. The envelop curves are derived for several different levels of constant axial force, which are defined by the user and incorporate three levels in compressive axial force, zero axial force, and two levels in tensile axial force. Such an arrangement enables the user with a proper selection of axial force range of interest. The envelope curve corresponding to an axial force between these prespecified levels is established using extrapolation. The graphical representation of the shear stiffness transition due to varying axial forces is illustrated in Figure 1(b). As representative cases, the analytical predictions obtained with and without the new formulations are illustrated in Figure 2. As observed, while a good agreement was achieved between experiment and analysis with shear, a significant difference was obtained between experiment and analysis without shear. A more detailed comparison can be found elsewhere [36, 38, 39].

\section{Analytical Model and Input Ground Motion}

In order to investigate the effect of multiple earthquake ground motions on the inelastic response of a bridge, a reinforced concrete bridge structure, severely damaged by the Northridge earthquake of 17 January 1994, is selected. The bridge under consideration is a ramp structure 


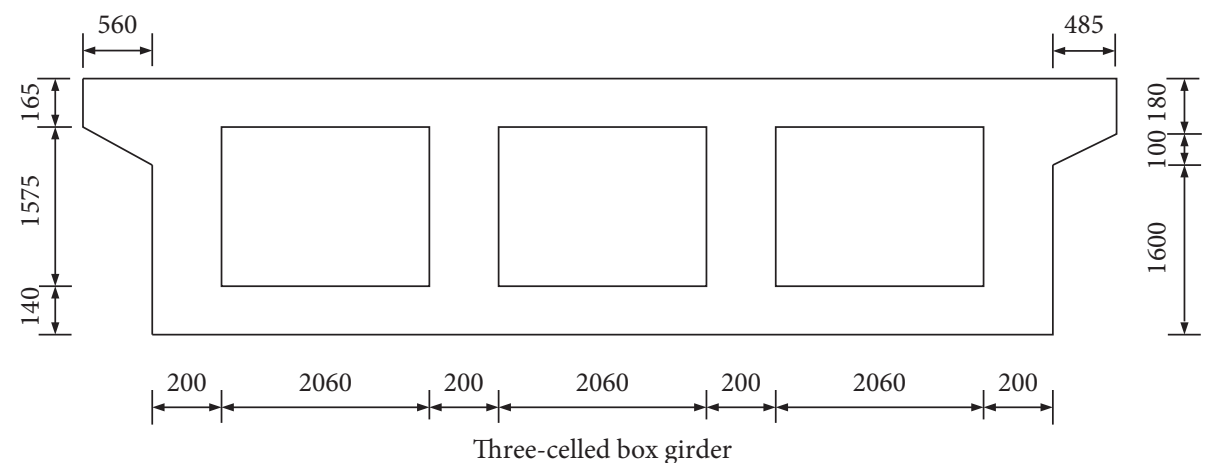

(a)

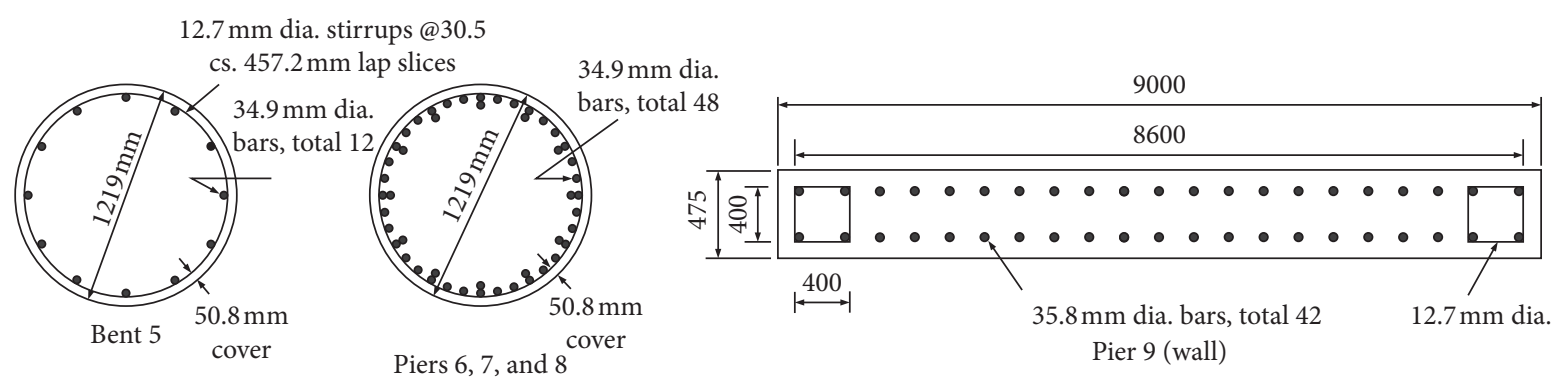

(b)

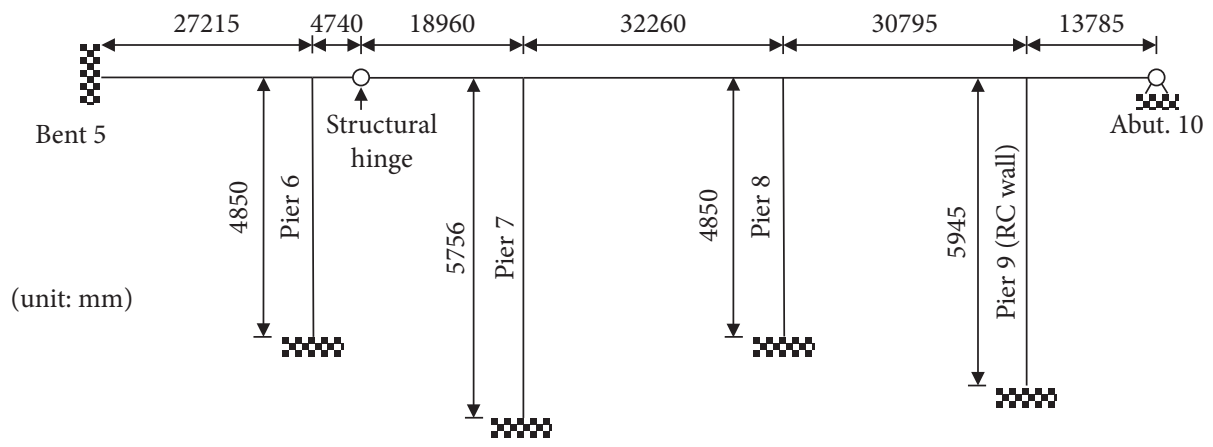

(c)

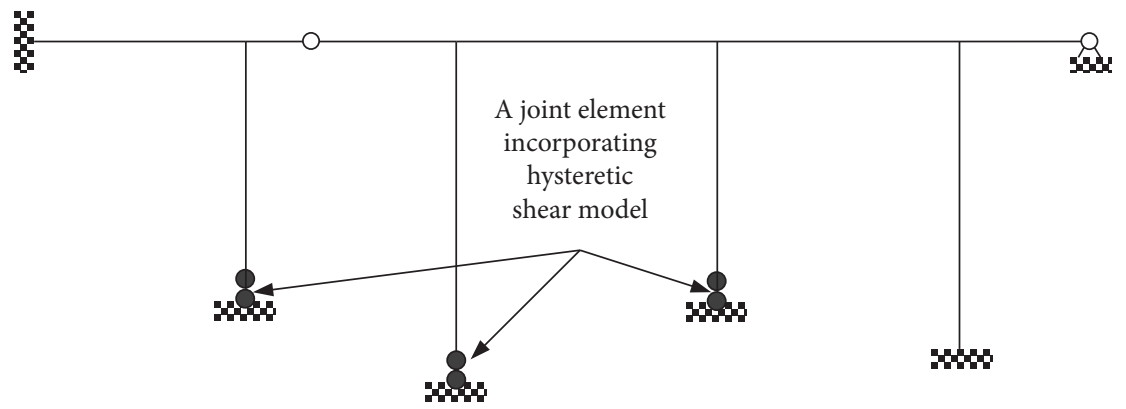

(d)

Figure 3: Analytical model of collector distributor 36. (a) Three-celled box girder cross section. (b) Cross sections of the columns and pier wall. (c) Structural model (flexure-axial interaction). (d) Structural model with shear (flexure-shear-axial interaction).

(Collector Distributor 36), which continues on a line close to that of the main freeway, La Cienega-Venice Boulevard sector of the I-10 [40]. The choice of the bridge structure is intuitive. It is appreciated that the chosen bridge structure is not as conclusive as a damaged bridge structure under the two Turkey earthquakes. However, since very few literature studies are available on the damaged reinforced concrete bridge structure under the two successive Turkey earthquakes, the bridge is selected for comparative analyses.

3.1. Analytical Model of Santa Monica Collector Distributor 36. The deck of the ramp structure consists of a three-celled box girder and is carried over the multicolumn bent 5 , then 
TABLE 1: Peak ground acceleration of the selected records.

\begin{tabular}{lccc}
\hline \multirow{2}{*}{ Station } & \multicolumn{3}{c}{ Peak ground acceleration $(\mathrm{g})$} \\
& Longitudinal & Transverse & Vertical \\
\hline $\begin{array}{l}\text { Duzce (Kocaeli EQ) } \\
\begin{array}{l}\text { Duzce (Duzce-Bolu EQ) } \\
\text { Pacoima Dam (San }\end{array}\end{array} 0^{\text {Fernando EQ) }}$ & 0.361 & 0.310 & 0.205 \\
$\begin{array}{l}\text { City Hall grounds } \\
\text { (Northridge EQ) }\end{array}$ & 1.174 & 0.377 & 0.345 \\
\hline
\end{tabular}

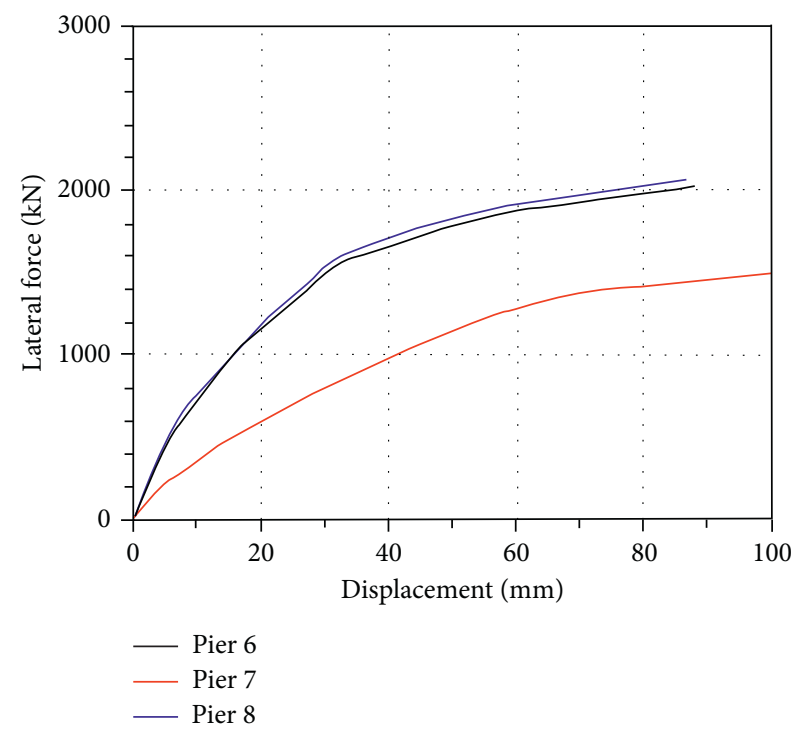

FIgURE 4: Static lateral force-displacement response of piers.

Table 2: Static response characteristics.

\begin{tabular}{lccc}
\hline Parameters & Pier 6 & Pier 7 & Pier 8 \\
\hline Applied axial force $(\mathrm{kN})$ & 2395 & 2830 & 3180 \\
Lateral force capacity $(\mathrm{kN})$ & 2030 & 1645 & 2065 \\
Yield displacement $(\mathrm{mm})$ & 32 & 62 & 32 \\
Yield curvature $(1 / \mathrm{m})$ & 0.00342 & 0.00489 & 0.00344 \\
\hline
\end{tabular}

over three single-column bents 6,7 , and 8 , and over the pier wall of bent 9 . In the deck, a movement joint forming a structural hinge is placed just under $5 \mathrm{~m}$ away from the bent 6. The presence of this movement joint may allow both relative displacement and rotation to occur between the ends of the deck. The columns of all bents consist of $1219 \mathrm{~mm}$ diameter reinforced concrete circular sections. Column longitudinal reinforcement is identical for piers 6,7 , and 8 , while less longitudinal reinforcement is employed in the columns of bent 5 . Cross sections of three-celled box girder and cross sections of columns and pier wall are shown in Figures 3(a) and 3(b), respectively. The general layout of the ramp structure is shown in Figure 3(c), which represents the flexure-axial interactive model. In this model, five cubic inelastic elements are employed in the piers, with shorter elements at the base and top of the piers and longer elements toward the center. This arrangement allows plastic hinges to be captured accurately, and hence, the inelastic behavior. To account for the effect of shear, each pier of the ramp structure is modeled by a combination of cubic inelastic elements with a single joint element representing the developed axial-shear interaction at the bottom of the piers. Thus, flexure-shear-axial interaction will be simulated through this model. The graphical representation of the model is illustrated in Figure 3(d). The longitudinal reinforcement is continuous to the bottom of the footing, providing moment resistance. The connection between the piers and the deck is also effectively continuous. Detailed description regarding the bridge structure can be found in reference [41].

Use is made of MCFT [34] to define the input parameters of the new shear element. For this purpose, each pier was analyzed for several levels of constant axial force. These levels are $10 \%, 20 \%$, and $30 \%$ of compressive axial force capacity, zero axial force, and $10 \%$ and $30 \%$ of the tensile axial force capacity (where both capacity values were calculated according to ACI 318-14 [42]). Since the exceedance of $15 \%$ of compressive axial force capacity is not common for reinforced concrete bridge piers [43], the selection of the above axial force range can be considered as an upper bound.

3.2. Input Ground Motion. Two sets of accelerograms (four in total) are selected for comparative dynamic analyses. One set of accelerograms is Kocaeli (K) and Duzce (D) earthquakes, recorded at the same station, Duzce under the two Turkey earthquakes, Kocaeli of August 1999 and Duzce of November 1999, respectively. The other set of accelerograms is San Fernando (F) and Northridge (N) earthquakes, recorded at Pacoima Dam, San Fernando earthquake of 1971 and the City Hall grounds, Northridge earthquake of 1997, respectively. Whereas the former set may represent the effect of damage accumulation on the structure due to their successive nature in the same area, the latter set can be considered as a benchmark since the two stations are not identical although they are geographically proximate. Nonetheless, it is worth noting that the chosen ground motions are not sufficient enough and rather intuitive. However, since the purpose of the present study is to assess the response of the bridge structure experiencing multiple main shocks recorded at almost identical stations with a time interval, the study can be considered as exploratory comparative analyses on the damage accumulation with and without shear. The peak ground accelerations of all components for the four earthquake ground motions are given in Table 1.

\subsection{Inelastic Seismic Analysis Results}

3.3.1. Static Analysis for Piers. Static analysis of each pier was carried out using the MCFT [34] for preliminary evaluation of the pier capacities. Gravity loads assessed from the cross-sectional areas of the box girder and the piers were applied as axial force at the top of each pier. Figure 4 shows the lateral force-displacement response of each pier in the transverse direction. Comparison of static response of piers shows that while the response of piers 6 and 8 is nearly 


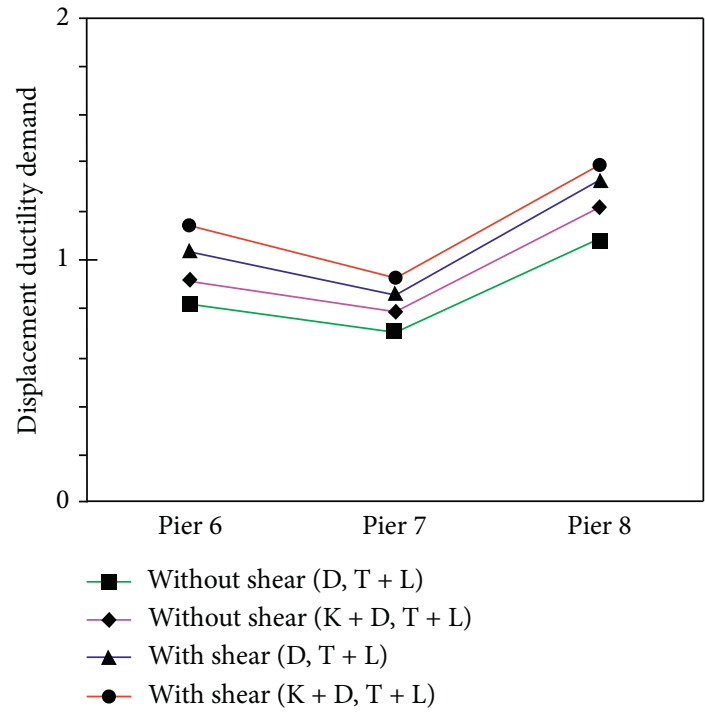

(a)

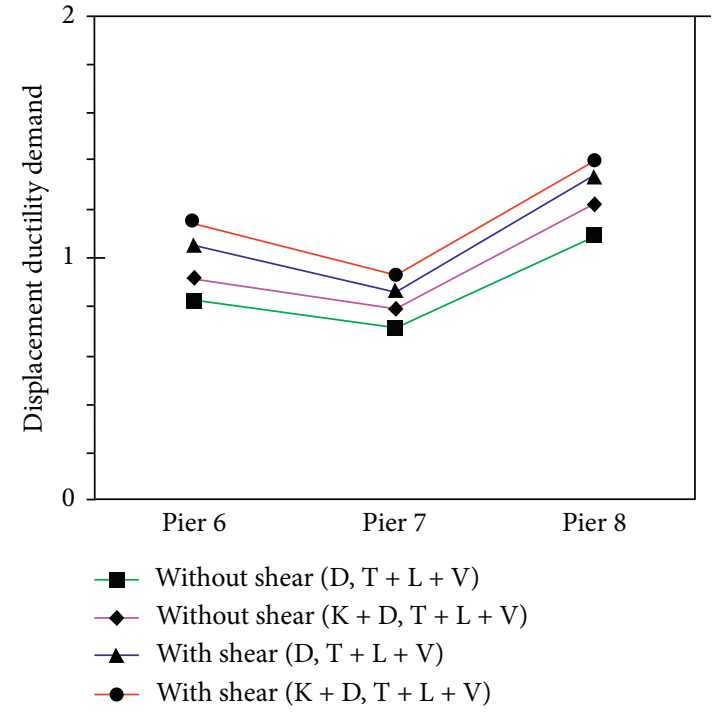

(b)

Figure 5: Comparison of ductility demand under D and $\mathrm{K}+\mathrm{D}$ earthquakes. (a) Under biaxial input ground motions. (b) Under triaxial input ground motions.

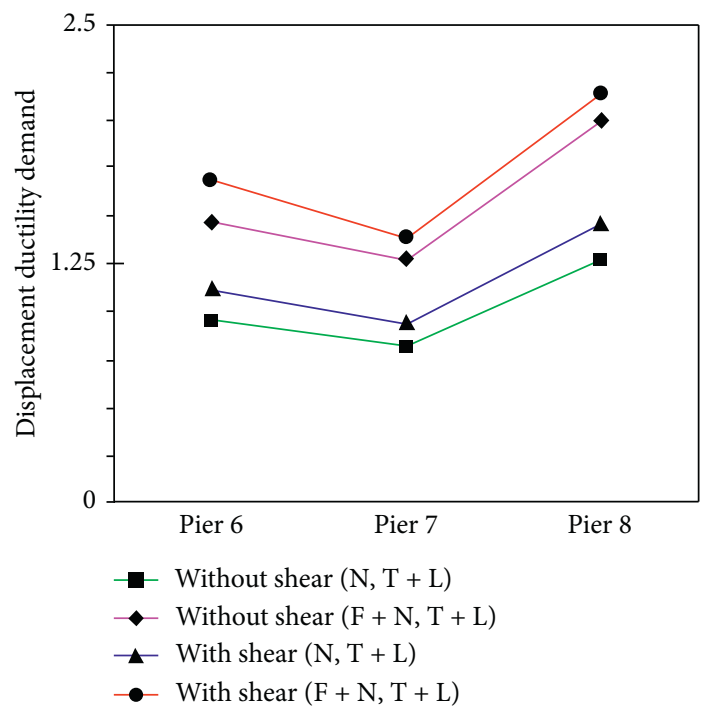

(a)

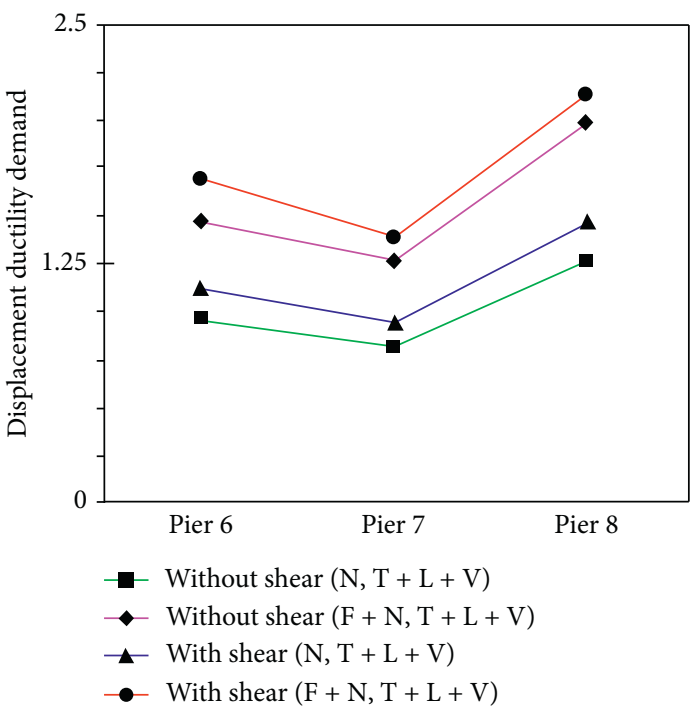

(b)

Figure 6: Comparison of ductility demand under $\mathrm{N}$ and $\mathrm{F}+\mathrm{N}$ earthquakes. (a) Under biaxial input ground motions. (b) Under triaxial input ground motions.

TABle 3: Maximum transverse displacement under bi- and triaxial input ground motions (in $\mathrm{mm}$ ).

\begin{tabular}{lccccccc}
\hline \multirow{2}{l}{$\begin{array}{l}\text { Input ground } \\
\text { motion }\end{array}$} & \multicolumn{3}{c}{ Without shear } & \multicolumn{3}{c}{ With shear } \\
& & Pier 6 & Pier 7 & Pier 8 & Pier 6 & Pier 7 & Pier 8 \\
\hline \multirow{4}{*}{ Biaxial } & $\mathrm{D}$ & 26.19 & 43.72 & 34.73 & 33.28 & 53.11 & 42.59 \\
& $\mathrm{~K}+\mathrm{D}$ & 29.31 & 48.85 & 39.01 & 36.45 & 57.48 & 44.68 \\
& $\mathrm{~N}$ & 30.62 & 50.52 & 40.67 & 35.68 & 58.05 & 46.80 \\
& $\mathrm{~F}+\mathrm{N}$ & 46.84 & 78.70 & 63.77 & 54.00 & 85.94 & 68.39 \\
\hline \multirow{4}{*}{ Triaxial } & $\mathrm{D}$ & 26.48 & 44.13 & 34.95 & 33.54 & 53.49 & 42.76 \\
& $\mathrm{~K}+\mathrm{D}$ & 29.33 & 48.88 & 38.97 & 36.47 & 57.57 & 44.57 \\
& $\mathrm{~N}$ & 30.60 & 50.51 & 40.63 & 35.62 & 57.97 & 46.74 \\
& $\mathrm{~F}+\mathrm{N}$ & 46.77 & 78.54 & 63.68 & 53.75 & 86.00 & 68.36 \\
\hline
\end{tabular}

identical, the response of pier 7 displays much less stiffness than that of piers 6 and 8. It is also noteworthy that the pier 7 experiences the greatest displacement. This can be attributed to different heights between the piers, being the tallest for pier 7. Static response characteristics are summarized in Table 2. As observed, pier 8 carries a greater axial force due to adjacent long spans. While the yield displacement is identical $(32 \mathrm{~mm})$ for piers 6 and 8 , that is much greater $(62 \mathrm{~mm})$ for pier 7 .

3.3.2. Nonlinear Inelastic Time-History Response. Nonlinear inelastic time-history analyses were carried out for both flexure-axial only model and flexure-shear-axial interaction 

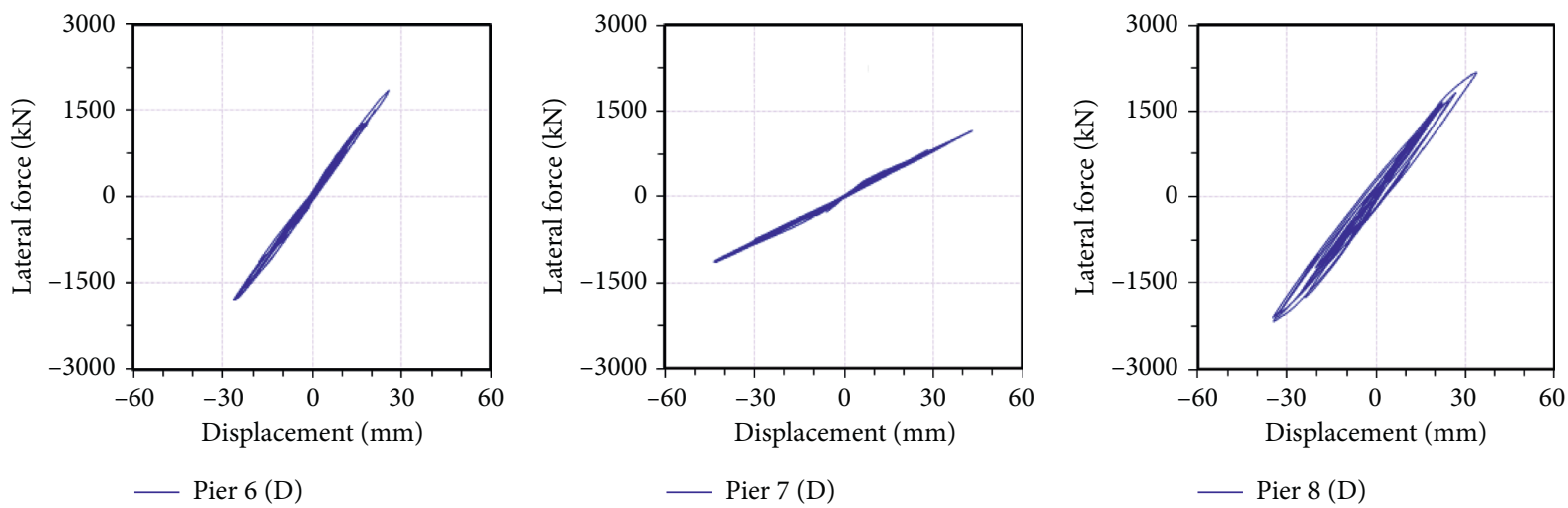

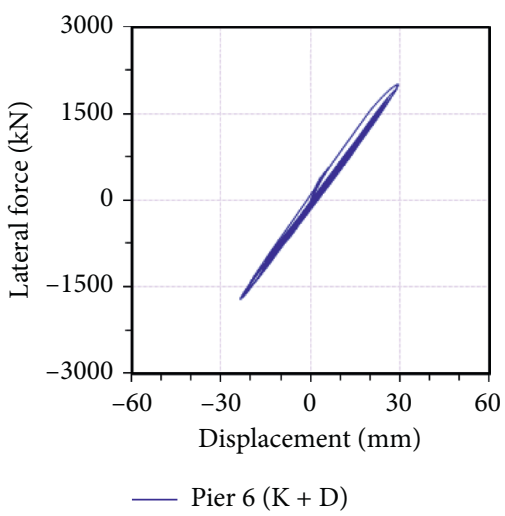

(a)

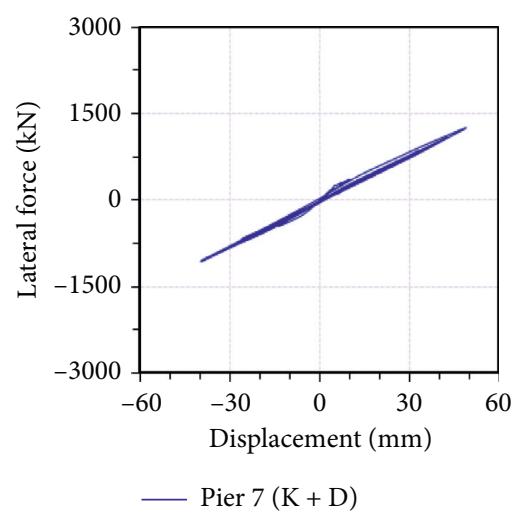

(b)

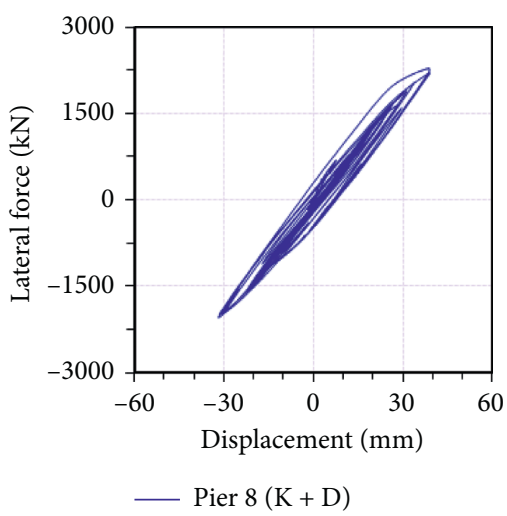

(c)

Figure 7: Transverse hysteretic response of the flexure-axial model subjected to biaxial input ground motions of $\mathrm{D}$ and $\mathrm{K}+\mathrm{D}$ earthquakes. (a) Pier 6. (b) Pier 7. (c) Pier 8.
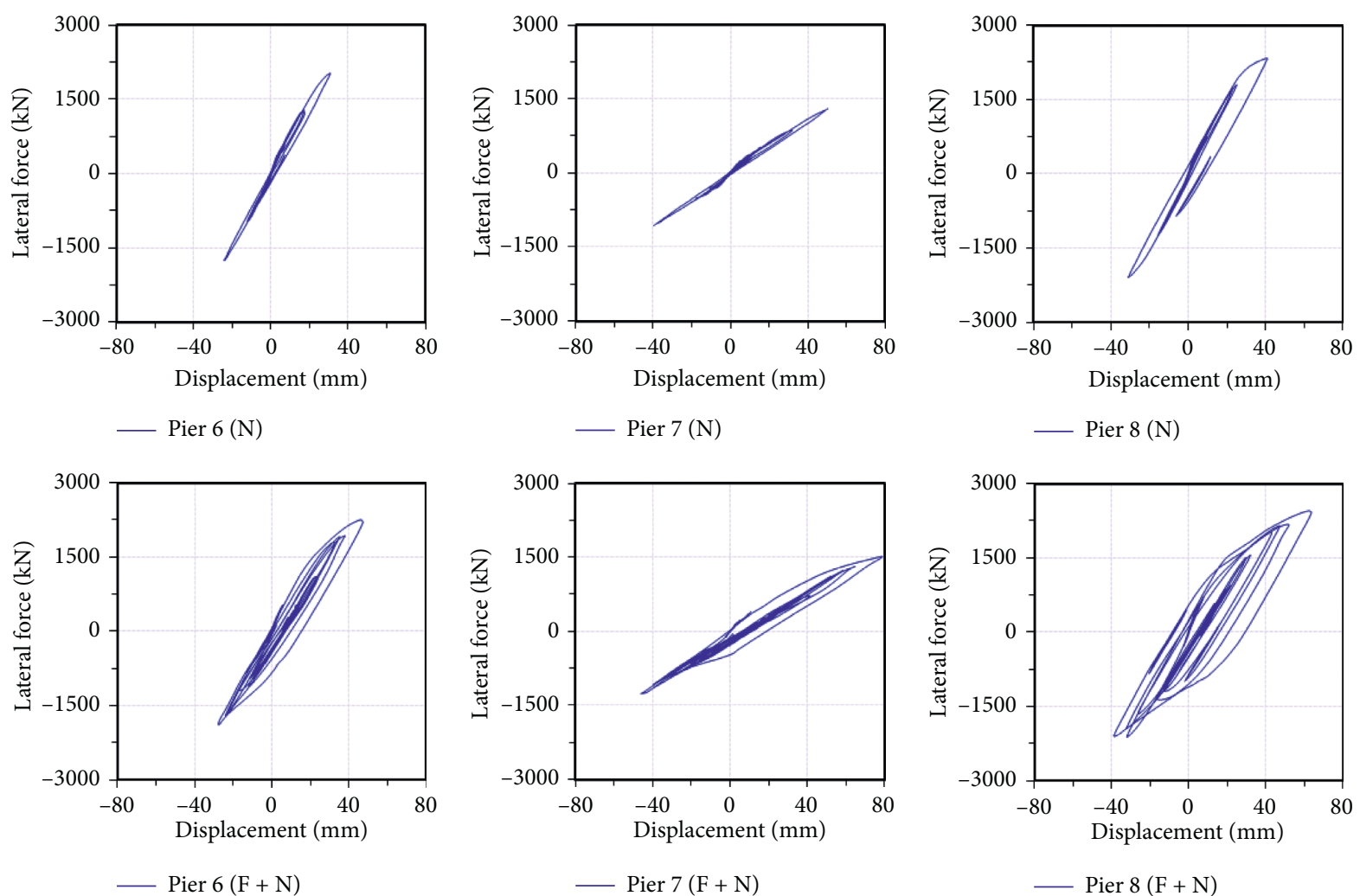

(a)

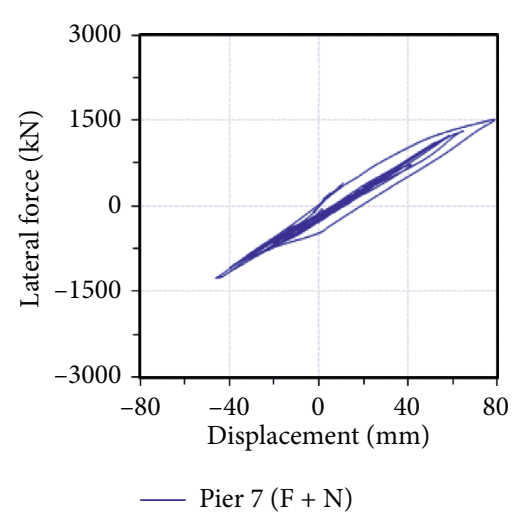

(b)

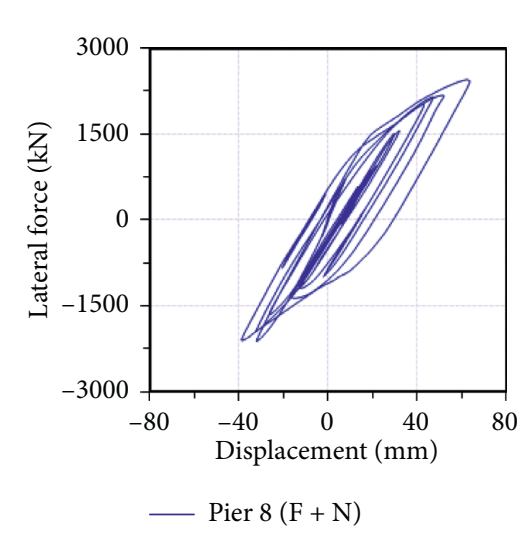

(c)

FIgURE 8: Transverse hysteretic response of the flexure-axial model subjected to biaxial input ground motions of $\mathrm{N}$ and $\mathrm{F}+\mathrm{N}$ earthquakes. (a) Pier 6. (b) Pier 7. (c) Pier 8. 

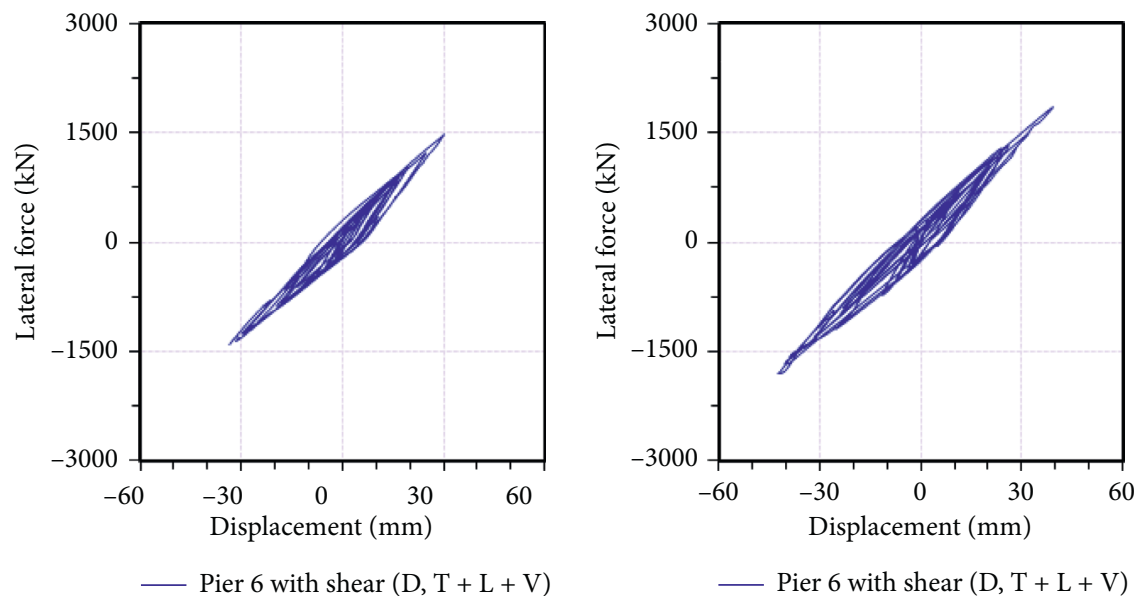

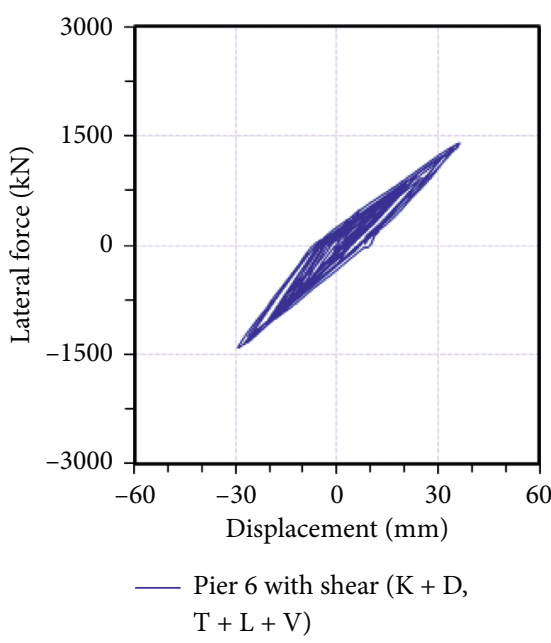

(a)

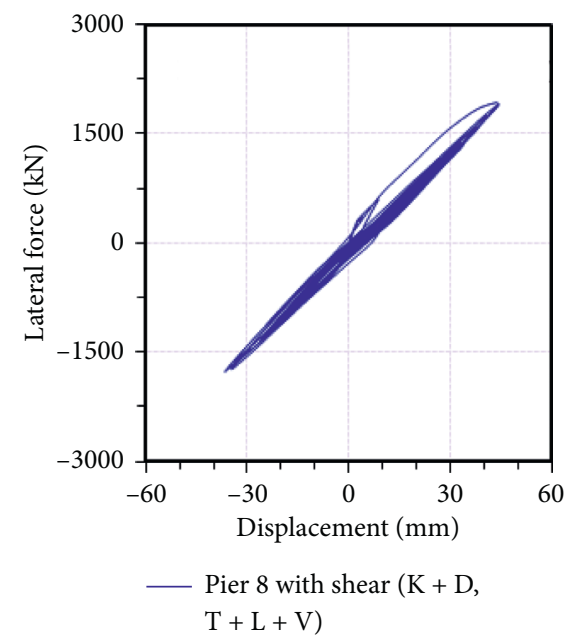

(b)

Figure 9: Transverse hysteretic response of the flexure-shear-axial interaction model subjected to triaxial input ground motions of $\mathrm{D}$ and $\mathrm{K}+\mathrm{D}$ earthquakes. (a) Pier 6. (b) Pier 8.

model of the bridge structure, depicted in Figures 3(c) and $3(\mathrm{~d})$, respectively. Each of the models was subjected to single and multiple earthquakes of biaxial (transverse $(\mathrm{T})$ and longitudinal $(\mathrm{L})$ ) and triaxial (transverse $(\mathrm{T})$, longitudinal $(\mathrm{L})$, and vertical $(\mathrm{V})$ ) ground motions. In Figure $5, \mathrm{~T}+\mathrm{L}$ indicates the time-history analysis subjected to both transverse and longitudinal ground motions, while $\mathrm{T}+\mathrm{L}+\mathrm{V}$ points out the analysis subjected to transverse, longitudinal, and vertical ground motions.

Figures 5(a) and 5(b) show comparisons of displacement ductility demand for piers in the transverse direction, subjected to single (D) and multiple earthquakes $(K+D)$ under biaxial and triaxial input ground motions, respectively. In general, the analyses under multiple earthquakes show higher displacement ductility demand than those under single earthquake, being approximately $10 \%$ increase. Also depicted in the figure are comparisons between with and without shear. As observed, the analyses with shear exhibit higher displacement ductility demand than those without shear, up to approximately $30 \%$ increase for pier 6 .
Shown in Figures 6(a) and 6(b) are comparisons of displacement ductility demand for piers in the transverse direction, subjected to single $(\mathrm{N})$ and multiple earthquakes $(\mathrm{F}+\mathrm{N})$ under biaxial and triaxial input ground motions, respectively. Whereas the same trend of displacement ductility demand increase is observed in Figure 5, the discrepancy between single and multiple earthquakes is rather significant, being approximately $50 \%$ increased ductility demand for both with and without shear. It is therefore noteworthy that displacement response can be significantly affected by the applied ground motion characteristics. However, a minor effect of vertical ground motion on the ductility demand is observed from the figures. The maximum displacement in the transverse direction is summarized in Table 3. As observed in general, the maximum displacement with shear is greater than that without shear.

Further investigation was carried out for the effect of multiple earthquakes in terms of the hysteretic response of piers in the transverse direction. Figures 7 and 8 show comparisons of transverse hysteretic response of piers for 


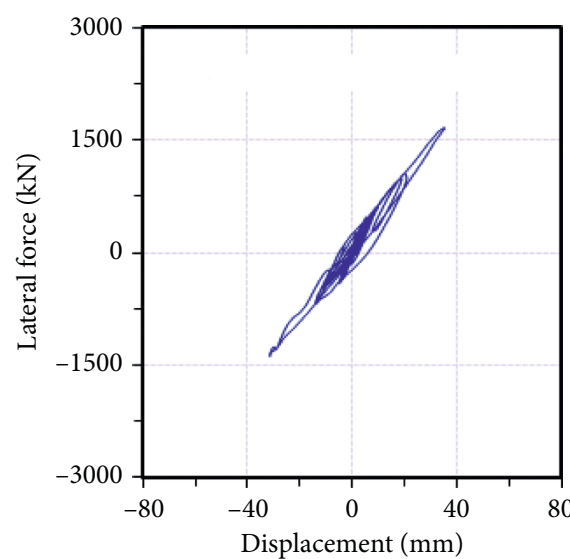

_ Pier 6 with shear $(\mathrm{N}, \mathrm{T}+\mathrm{L}+\mathrm{V})$

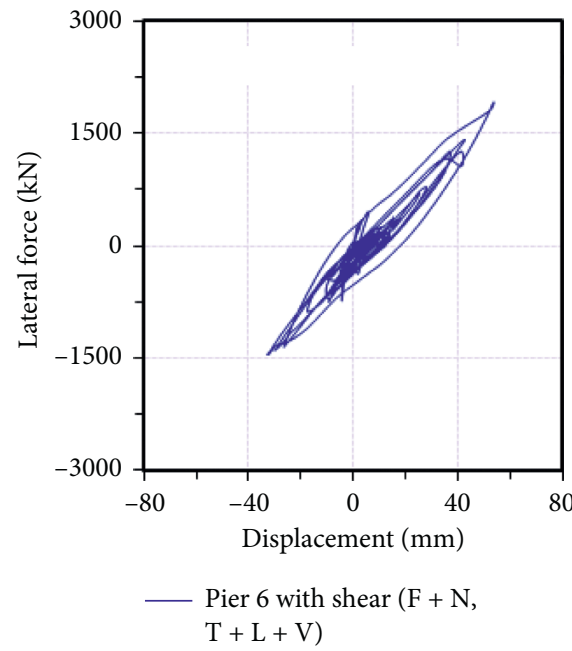

(a)
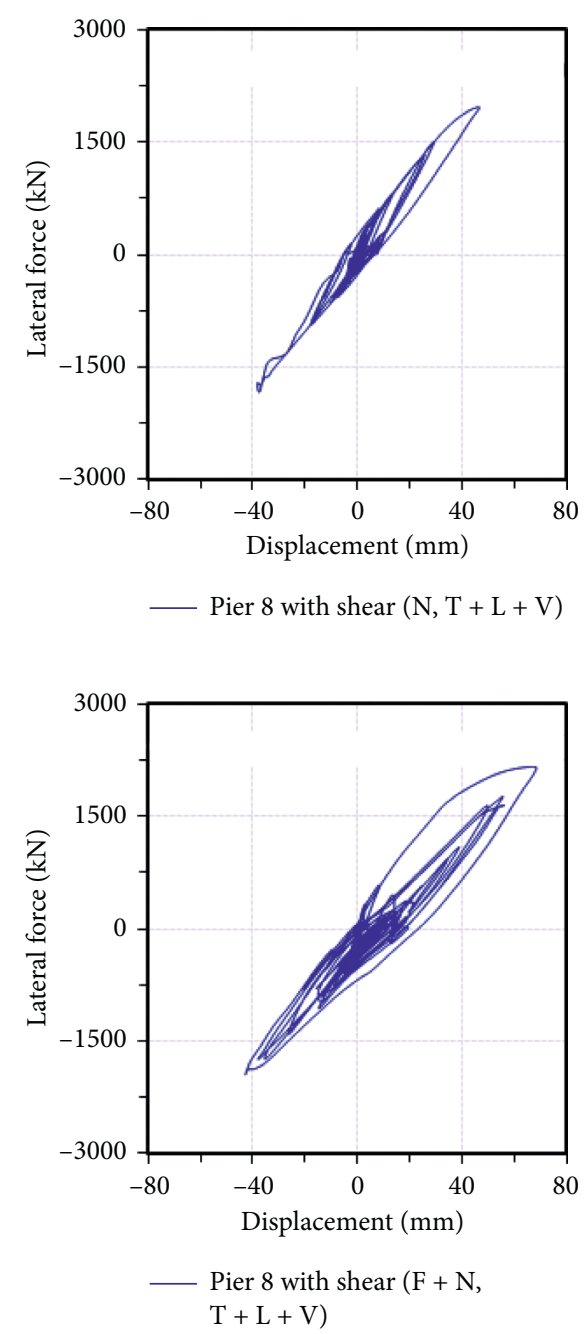

(b)

FiguRE 10: Transverse hysteretic response of the flexure-shear-axial interaction model subjected to triaxial input ground motions of $\mathrm{N}$ and $\mathrm{F}+\mathrm{N}$ earthquakes. (a) Pier 6. (b) Pier 8.

flexure-axial only model cases between single and multiple earthquakes of biaxial input ground motions, subjected to a series of Turkey and USA earthquakes, respectively. For both cases in general, the response under multiple earthquake motions exhibits more pronounced increased inelastic displacement than that under single earthquake motion. In addition, the former experiences a number of inelastic cycles as well as low cycles. This implies that the pier stiffness will decrease with the number of cycles experienced, even if the maximum ductility discrepancy between single and multiple earthquake motions is small (10\% difference in the former case), as shown in Figure 5. In other words, the damage to the structure subjected to multiple earthquake motions is more than that under single earthquake motion. Hence, the best measure of damage evaluation should include both the maximum displacement experienced and the stiffness due to the number of cycles. This also stresses the importance of response analysis under multiple earthquake motions.

In order to investigate the effect of multiple earthquakes on the response with shear, comparisons of hysteretic response are made for piers 6 and 8 of the flexure-shear-axial interaction model. Figures 9 and 10 show the transverse hysteretic response for piers 6 and 8 of the flexure-shearaxial interaction model cases between single and multiple earthquakes of triaxial input ground motions, subjected to series of Turkey and USA earthquakes, respectively.

As observed, the response under multiple earthquakes experiences a greater displacement and shows more pronounced stiffness degradation. It is important to note from the response with shear under multiple earthquakes that once single cycle of maximum displacement occurs, the reloading stiffness is significantly reduced in comparison with the stiffness of the first cycle. This indicates that multiple earthquake motions combined with shear affect the energy dissipation capacities of piers, leading to the reduction of stiffness of piers and hence the damage mode.

Comparisons of the response with and without shear are made to investigate the effect of shear on the damage mode of the bridge structure subjected to multiple earthquakes. Figures 11 and 12 illustrate the transverse displacement 


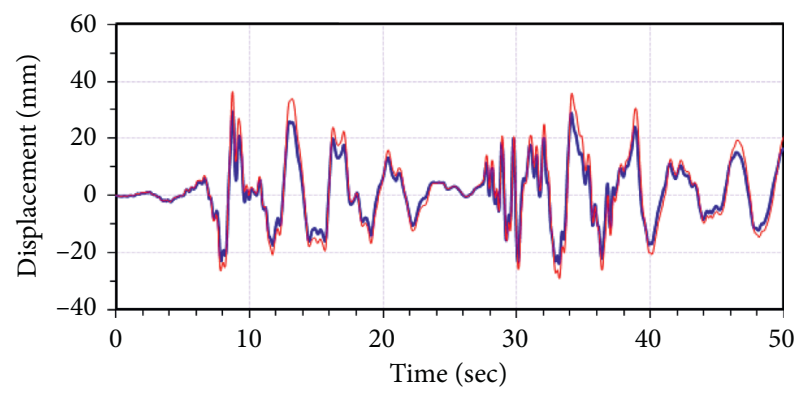

- Without shear (pier 6, K+D, T + L)

— With shear (pier 6, K+ D, T+ L)

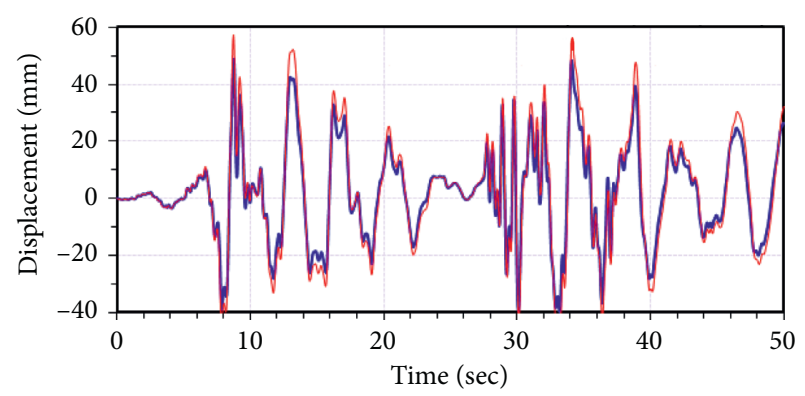

- Without shear (pier 7, K+ D, T + L)

— With shear (pier 7, K+ D, T + L)

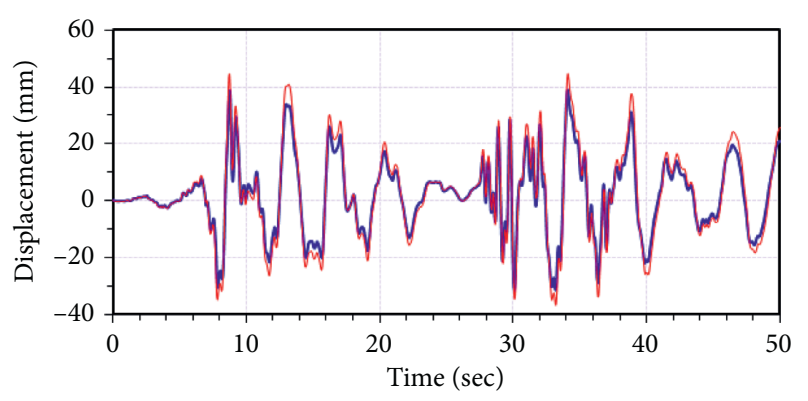

- Without shear (pier 8, K + D, T + L)

W With shear (pier $8, \mathrm{~K}+\mathrm{D}, \mathrm{T}+\mathrm{L}$ )

FIgURE 11: Transverse displacement response without and with shear subjected to biaxial input ground motions of multiple earthquakes, $\mathrm{K}+\mathrm{D}$.

response without and with shear subjected to biaxial input ground motions of multiple earthquakes, $\mathrm{K}+\mathrm{D}$ and $\mathrm{F}+\mathrm{N}$, respectively. The increase in total displacement with the inclusion of shear is clearly observed in the figures. This indicates that piers are subjected to higher displacement demands due to shear (approximately 20\% higher in general), particularly for piers 6 and 8 . This may be attributed to the irregular bridge structure under consideration, where piers have different heights, and thus, the ductility demand may be concentrated on a particular member. The breakdown of total displacement into its components shows that shear displacement is pronounced. The contribution of shear displacement to total displacement reaches a significant level, approximately $45 \%$ and $40 \%$ for piers 6 and 8 , and a lower value of $30 \%$ for pier 7 . The maximum transverse response with reference to displacement components is summarized in Table 4.
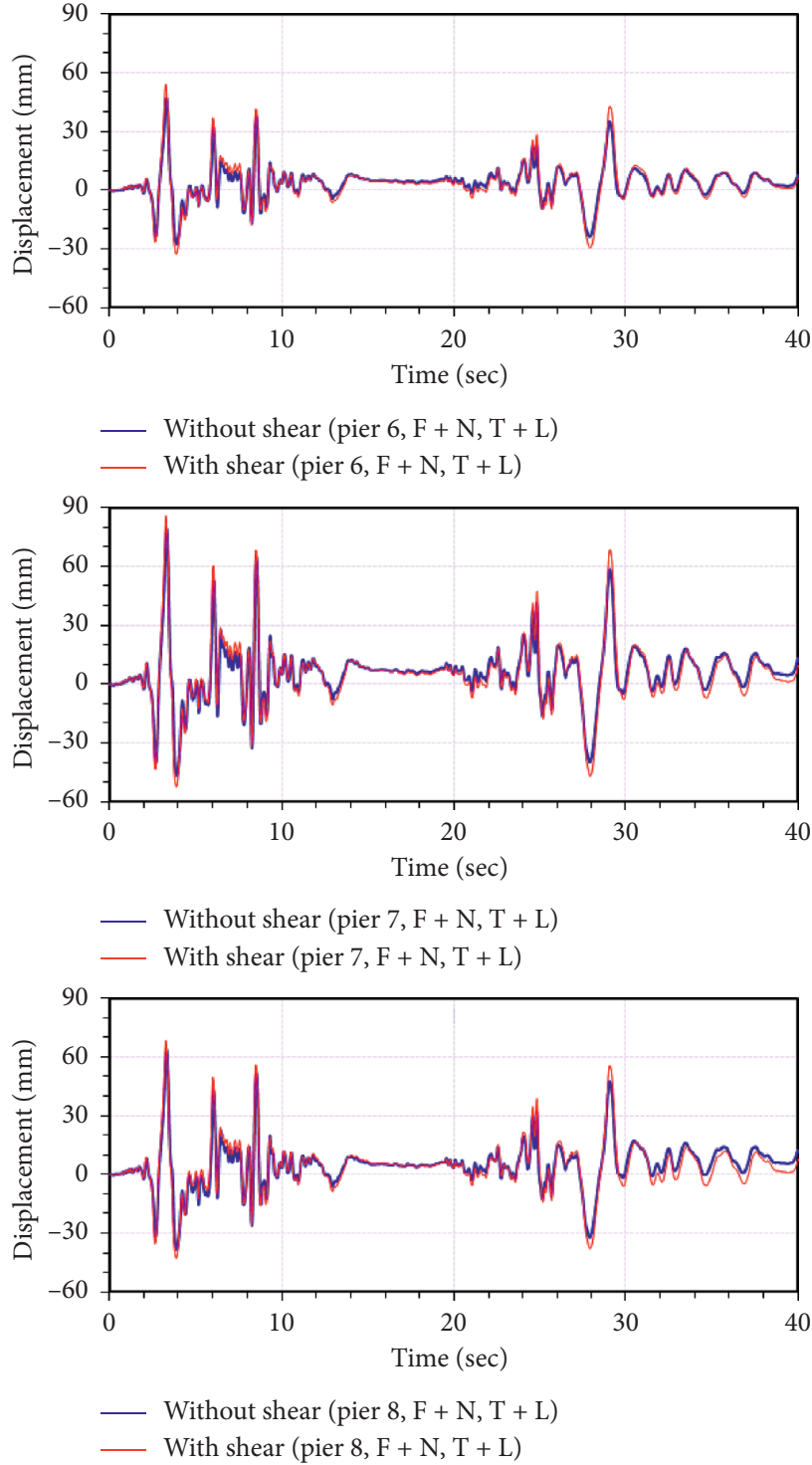

FIgURE 12: Transverse displacement response without and with shear subjected to biaxial input ground motions of multiple earthquakes, $\mathrm{F}+\mathrm{N}$.

Figures 13 and 14 show comparisons of the corresponding transverse lateral force response without and with shear subjected to biaxial input ground motions of multiple earthquakes, $\mathrm{K}+\mathrm{D}$ and $\mathrm{F}+\mathrm{N}$, respectively. Reduction in lateral force carrying capacity for the response with shear is obvious for piers 6 and 8 , although vibration cycles are nearly identical. This explains that those piers are expected to experience significant stiffness degradation due to both increase in displacement and decrease in lateral force carrying capacity. This is supported further by the evaluation of hysteretic response.

Figure 15 illustrates the transverse hysteretic response for piers 6 and 8 subjected to biaxial input ground motions of multiple earthquakes, $\mathrm{F}+\mathrm{N}$. While the response without shear shows relatively stable hysteresis loops, that with shear exhibits severe stiffness degradation, increased displacement, and sudden drop in lateral force carrying capacity. In 
TABle 4: Maximum transverse displacement component for the model with shear (in $\mathrm{mm}$ ).

\begin{tabular}{|c|c|c|c|c|c|c|c|c|c|c|}
\hline \multirow{2}{*}{\multicolumn{2}{|c|}{$\begin{array}{l}\text { Input ground } \\
\text { motion }\end{array}$}} & \multicolumn{3}{|c|}{ Pier 6} & \multicolumn{3}{|c|}{ Pier 7} & \multicolumn{3}{|c|}{ Pier 8} \\
\hline & & Total & Flexure & Shear & Total & Flexure & Shear & Total & Flexure & Shear \\
\hline \multirow{4}{*}{ Biaxial } & $\mathrm{D}$ & 33.28 & 20.68 & 12.70 & 53.11 & 40.83 & 12.28 & 42.59 & 26.04 & 16.55 \\
\hline & $\mathrm{K}+\mathrm{D}$ & 36.45 & 20.35 & 16.10 & 57.48 & 41.08 & 16.40 & 44.68 & 28.31 & 16.37 \\
\hline & $\mathrm{N}$ & 35.68 & 24.32 & 12.36 & 58.05 & 47.05 & 11.00 & 46.80 & 30.34 & 16.46 \\
\hline & $\mathrm{F}+\mathrm{N}$ & 54.00 & 29.22 & 24.78 & 85.94 & 62.25 & 23.69 & 68.39 & 40.88 & 27.51 \\
\hline \multirow{4}{*}{ Triaxial } & $\mathrm{D}$ & 33.54 & 20.92 & 16.62 & 53.49 & 41.24 & 12.25 & 42.76 & 25.64 & 17.12 \\
\hline & $\mathrm{K}+\mathrm{D}$ & 36.47 & 20.11 & 16.36 & 57.57 & 39.07 & 18.50 & 44.57 & 28.44 & 16.13 \\
\hline & $\mathrm{N}$ & 35.62 & 24.35 & 12.27 & 57.97 & 46.70 & 11.27 & 46.74 & 30.25 & 16.49 \\
\hline & $\mathrm{F}+\mathrm{N}$ & 53.75 & 29.32 & 24.43 & 86.00 & 59.46 & 26.54 & 68.36 & 40.08 & 28.28 \\
\hline
\end{tabular}
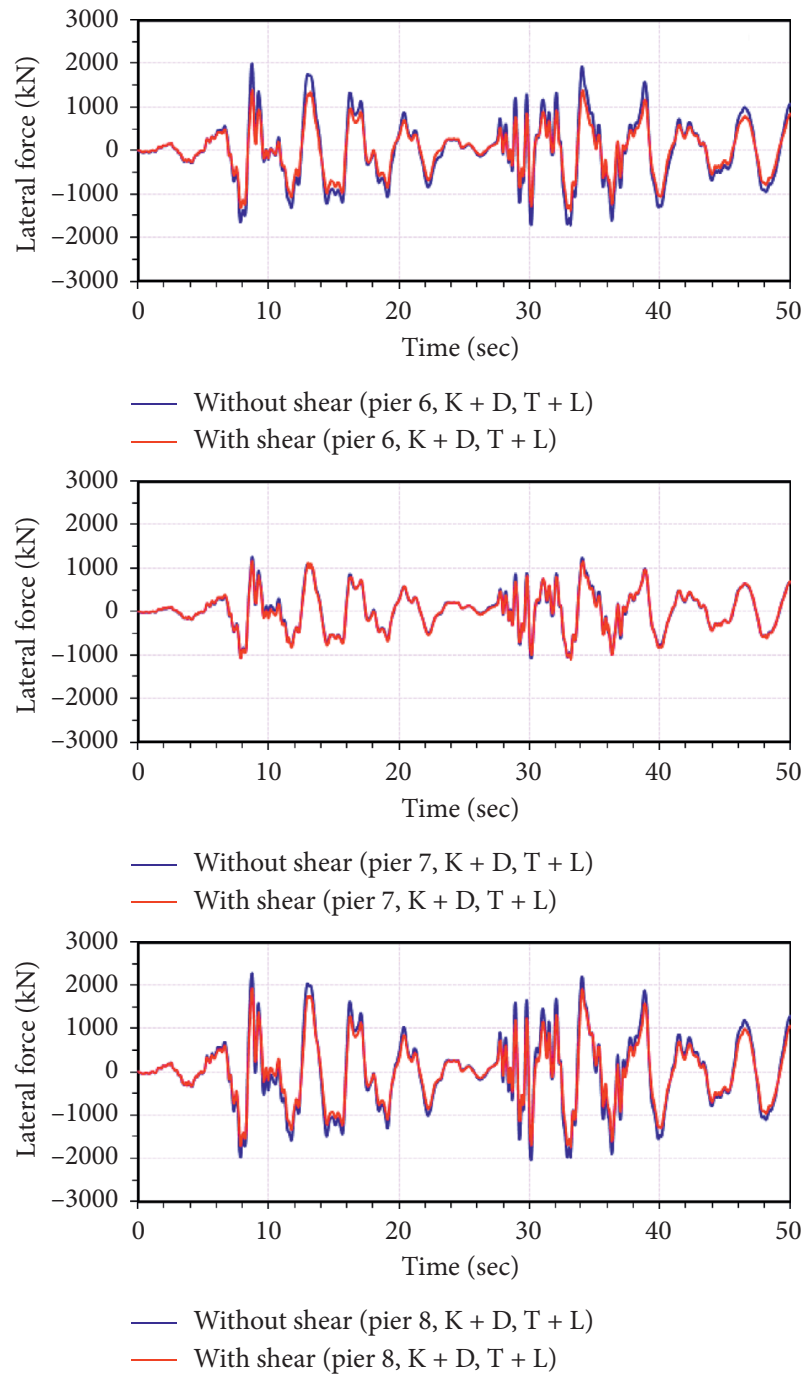

FIGURE 13: Transverse lateral force response without and with shear subjected to biaxial input ground motions of multiple earthquakes, $\mathrm{K}+\mathrm{D}$.

addition, the amount of energy absorbed and dissipated by piers can be significantly affected by the presence of shear. Particular emphasis is placed on the reloading stiffness, once the first cycle of maximum displacement is attained.
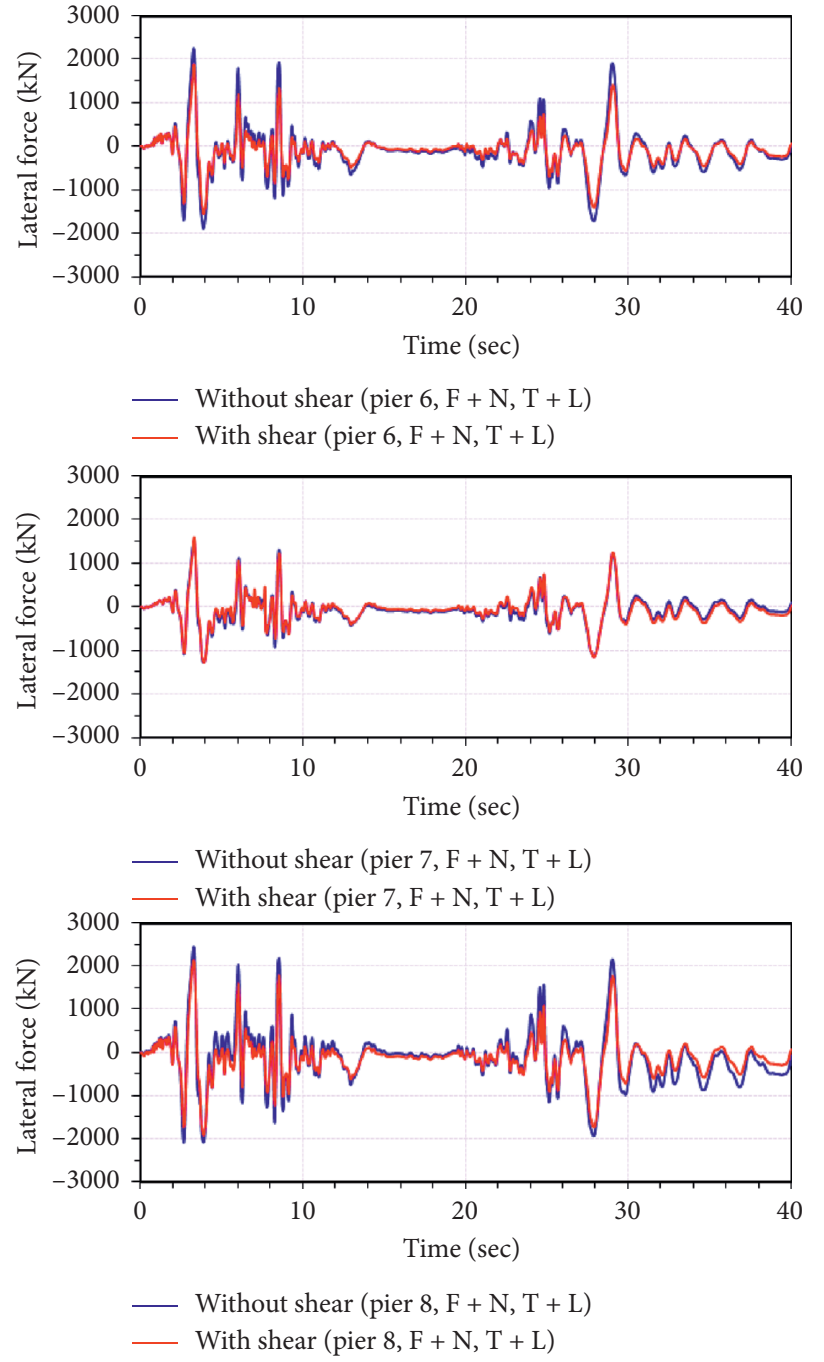

FIgURE 14: Transverse lateral force response without and with shear subjected to biaxial input ground motions of multiple earthquakes, $\mathrm{F}+\mathrm{N}$.

Significant reduction in stiffness (or pinching) is pronounced for the response with shear. This also suggests that shear under multiple earthquake motions affects the damage mode of piers. Table 5 shows the maximum transverse lateral 

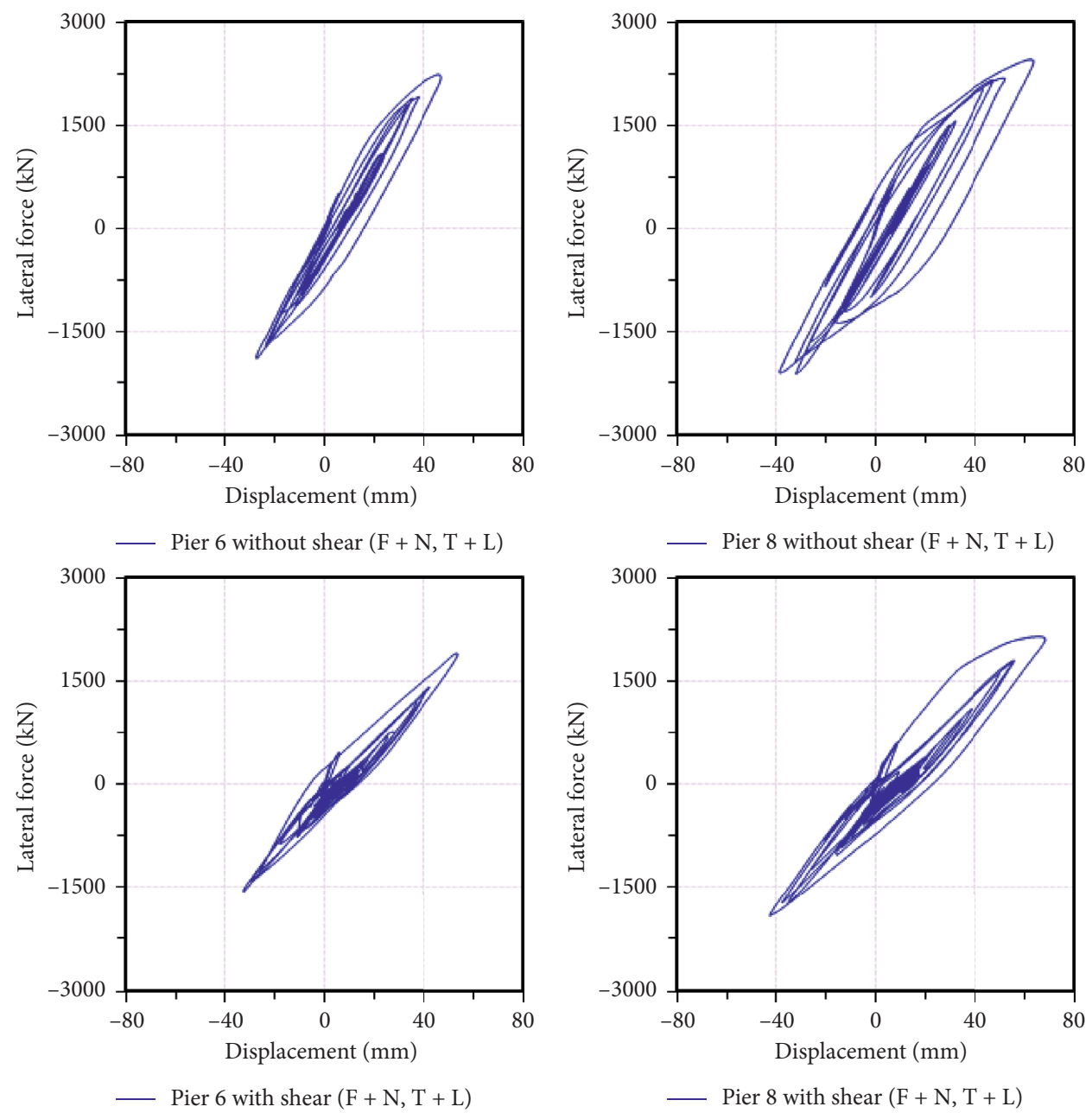

(a)

(b)

FIGURE 15: Transverse hysteretic response without and with shear subjected to biaxial input ground motions of multiple earthquakes, $\mathrm{F}+\mathrm{N}$. (a) Pier 6. (b) Pier 8.

TABLE 5: Maximum transverse lateral force without and with shear under multiple input ground motions $(\mathrm{kN})$.

\begin{tabular}{lccccc}
\hline \multirow{2}{*}{ Pier } & Analytical model & \multicolumn{2}{c}{$\begin{array}{c}\text { Biaxial input } \\
\text { motions }\end{array}$} & \multicolumn{2}{c}{ Triaxial input } \\
& & K+ Dotions & F+ N & K+D & F + N \\
\hline \multirow{2}{*}{ Pier 6 } & Without shear & 1992 & 2249 & 2008 & 2268 \\
& With shear & 1397 & 1884 & 1461 & 1900 \\
\hline \multirow{2}{*}{ Pier 7 } & Without shear & 1254 & 1498 & 1256 & 1490 \\
& With shear & 1160 & 1594 & 1317 & 1490 \\
\hline \multirow{2}{*}{ Pier 8 } & Without shear & 2281 & 2442 & 2289 & 2450 \\
& With shear & 1934 & 2145 & 1973 & 2163 \\
\hline
\end{tabular}

force response without and with shear. Considerable reduction in lateral force carrying capacity for the response with shear is clearly demonstrated.

\section{Conclusions}

Analytical study has been undertaken for the nonlinear inelastic seismic response of a reinforced concrete bridge under single and multiple earthquake ground motions. The analytical results show that the maximum displacement ductility demand imposed on the bridge piers depends primarily on the applied ground motion characteristics. Although the ductility demand under multiple earthquake motions is greater than that under single motion, the difference between the two cases is not significantly considerable. However, the stiffness degradation under multiple earthquake ground motions is more pronounced than that under single earthquake motion. This is supported by the hysteretic response of piers. The response shows that once the first cycle of maximum displacement is attained, loading stiffness of the second cycle under multiple earthquake ground motions is significantly reduced, in conjunction with a number of inelastic cycles, leading to experience more damage.

The effect of multiple earthquake ground motions on the response with shear is also investigated. Comparisons of the response without and with shear demonstrate that shear deformation is important. The response with shear exhibits the increase in displacement demand, decrease in lateral 
force carrying capacity, and energy absorption and dissipation capacity of piers. Moreover, shear deformation reaches a significant level (up to $45 \%$ to total deformation in this study).

In short, the multiple earthquake ground motions can considerably affect both flexural and shear stiffness degradation and deformation capacity in conjunction with shear. In addition, the response of bridge piers can be affected by the applied earthquake input motion sequence. Thus, the seismic analysis and design of bridges piers should account for the effect of multiple earthquake ground motions in order to assess the demand on such members properly.

\section{Data Availability}

This study is a numerical study, and the numerical study results may be sent upon requests.

\section{Disclosure}

Parts of figures and analytical results were employed from the paper by the first author, Do Hyung Lee. The paper is "Damage potential of RC bridge piers due to multiple earthquakes," $13^{\text {th }}$ World Conference on Earthquake Engineering, Paper no. 1020, Vancouver, B.C., Canada, 2004.

\section{Conflicts of Interest}

The authors declare that there are no conflicts of interest regarding the publication of this paper.

\section{Acknowledgments}

This work was supported by the National Research Foundation of Korea (NRF) grant funded by the Korea government (MSIT: Ministry of Science and ICT) (no. NRF-2018R1A2B6005716). The authors are grateful for the contribution by the first author.

\section{References}

[1] P. C. Jennings, "Engineering features of the San Fernando earthquake february 9, 1971," Technical Repor EERL 71-02, California Institute of Technology, Pasadena, CA, USA, 1971.

[2] A. S. Elnashai, "Analysis of the damage potential of the Kocaeli (Turkey) earthquake of 17 august 1999," Engineering Structures, vol. 22, no. 7, pp. 746-754, 2000.

[3] E. Uckan, V. A. Oven, and M. Erdik, "A study of the response of the Mustafa Inan viaduct to the Kocaeli earthquake," Bulletin of the Seismological Society of America, vol. 92, no. 1, pp. 483-498, 2002.

[4] M. Aschheim and E. Black, "Effects of prior earthquake damage on response of simple stiffness-degrading structures," Earthquake Spectra, vol. 15, no. 1, pp. 1-24, 1999.

[5] C. Amadio, M. Fragiacomo, and S. Rajgelj, "The effects of repeated earthquake ground motions on the non-linear response of SDOF systems," Earthquake Engineering \& Structural Dynamics, vol. 32, no. 2, pp. 291-308, 2003.

[6] N. Luco, P. Bazzuro, and C. A. Cornell, "Dynamic versus static computation of the residual capacity of mainshock-damaged building to withstand an aftershock," in Proceedings of 13th World Conference on Earthquake Engineering, Paper No. 2405, Vancouver, Canada, November 2004.
[7] G. D. Hatzigeorgiou and D. E. Beskos, "Inelastic displacement ratios for SDOF structures subjected to repeated earthquakes," Engineering Structures, vol. 31, no. 11, pp. 2744-2755, 2009.

[8] G. D. Hatzigeorgiou, "Behavior factors for nonlinear structures subjected to multiple near-fault earthquakes," Computers \& Structures, vol. 88, no. 5-6, pp. 309-321, 2010.

[9] S. Yaghmaaeri-Sabegh and J. Ruiz-Garcia, "Nonlinear response analysis of SDOF systems subjected to doublet earthquake ground motions: a case study on 2012 Varzaghan-Ahar events," Engineering Structures, vol. 110, pp. 281-292, 2016.

[10] M. Fragiacomo, C. Amadio, and L. Macorini, "Seismic response of steel frames under repeated earthquake ground motions," Engineering Structures, vol. 26, no. 13, pp. 2021-2035, 2004.

[11] Q. Li and B. R. Ellingwood, "Performance evaluation and damage assessment of steel frame buildings under main shock-aftershock earthquake sequences," Earthquake Engineering \& Structural Dynamics, vol. 36, no. 3, pp. 405-427, 2007.

[12] J. Ruiz-García and J. C. Negrete-Manriquez, "Evaluation of drift demands in existing steel frames under as-recorded farfield and near-fault mainshock-aftershock seismic sequences," Engineering Structures, vol. 33, no. 2, pp. 621-634, 2011.

[13] L. D. Sarno, "Effects of multiple earthquakes on inelastic structural response," Engineering Structures, vol. 56, pp. 673-681, 2013.

[14] M. Raghunandan and A. B. Liel, "Effect of ground motion duration on earthquake-induced structural collapse," Structural Safety, vol. 41, pp. 119-133, 2013.

[15] A. E. Abdelnaby and A. S. Elnashai, "Performance of degrading reinforced concrete frame systems under the Tohoku and Christchurch earthquake sequences," Journal of Earthquake Engineering, vol. 18, no. 7, pp. 1009-1036, 2014.

[16] F. Hosseinpour and A. E. Abdelnaby, "Effect of different aspects of multiple earthquakes on the nonlinear behavior of RC structures," Soil Dynamics and Earthquake Engineering, vol. 92, pp. 706-725, 2017.

[17] A. S. Elnashai and A. J. Papazoglou, "Procedure and spectra for analysis of RC structures subjected to strong vertical earthquake loads," Journal of Earthquake Engineering, vol. 1, no. 1, pp. 121-155, 1997.

[18] T. Takayanagi and W. C. Schnobrich, "Non-linear analysis of coupled wall systems," Earthquake Engineering \& Structural Dynamics, vol. 7, no. 1, pp. 1-22, 1979.

[19] M. Saatcioglu, A. T. Derecho, and W. G. Corley, "Modelling hysteretic behaviour of coupled walls for dynamic analysis," Earthquake Engineering \& Structural Dynamics, vol. 11, no. 5, pp. 711-726, 1983.

[20] M. Keshavarzian and W. C. Schnobrich, "Inelastic analysis of R/C coupled shear walls," Earthquake Engineering \& Structural Dynamics, vol. 13, no. 4, pp. 427-448, 1985.

[21] K. E. Galal and A. Ghobarah, "Flexural and shear hysteretic behaviour of reinforced concrete columns with variable axial load," Engineering Structures, vol. 25, no. 11, pp. 1353-1367, 2003.

[22] S. Prakash, A. Belarbi, and Y.-M. You, "Seismic performance of circular RC columns subjected to axial force, bending, and torsion with low and moderate shear," Engineering Structures, vol. 32, no. 1, pp. 46-59, 2010.

[23] E. J. Setzler and H. Sezen, "Model for the lateral behavior of reinforced concrete columns including shear deformations," Earthquake Spectra, vol. 24, no. 2, pp. 493-511, 2008. 
[24] H. Sezen and T. Chowdhury, "Hysteretic model for reinforced concrete columns including the effect of shear and axial load failure," Journal of Structural Engineering, ASCE, vol. 135, no. 2, pp. 139-146, 2009.

[25] A. S. Elnashai, V. Papanikolaou, and D. H. Lee, "ZeusNL-a program for inelastic dynamic analysis of structures, MidAmerica earthquake center," University of Illinois at UrbanaChampaign, IL, USA, 2002.

[26] H. M. Hilber, T. J. R. Hughes, and R. L. Taylor, "Improved numerical dissipation for time integration algorithms in structural dynamics," Earthquake Engineering \& Structural Dynamics, vol. 5, no. 3, pp. 283-292, 1977.

[27] D. H. Lee, E. Choi, and G. Zi, "Evaluation of earthquake deformation and performance for RC bridge piers," Engineering Structures, vol. 27, no. 10, pp. 1451-1464, 2005.

[28] D. H. Lee, D. Kim, and T. Park, "Earthquake response analysis of RC bridges using simplified modeling approaches," Journal of Sound and Vibration, vol. 324, no. 3-5, pp. 64-665, 2009.

[29] D. H. Lee, B. H. Kim, H. Lee, and J. S. Kong, "Seismic behavior of a buried gas pipeline under earthquake excitations," Engineering Structures, vol. 31, no. 5, pp. 1011-1023, 2009.

[30] D. H. Lee, D. Kim, and K. Lee, "Analytical approach for the earthquake performance evaluation of repaired/retrofitted RC bridge piers using time-dependent element," Nonlinear Dynamics, vol. 56, no. 4, pp. 463-482, 2009.

[31] D. H. Lee, J. Park, K. Lee, and B. H. Kim, "Nonlinear seismic assessment for the post-repair response of RC bridge piers," Composites Part B: Engineering, vol. 42, no. 5, pp. 1318-1329, 2011.

[32] J.-S. Jeon, R. DesRoches, and D. H. Lee, "Post-repair effect of column jackets on aftershock fragilities of damaged RC bridges subjected to successive earthquakes," Earthquake Engineering \& Structural Dynamics, vol. 45, no. 7, pp. 1149$1168,2016$.

[33] M. Saatcioglu and G. Ozcebe, "Response of reinforced concrete columns to simulated seismic loading," ACI Structural Journal, vol. 86, no. 1, pp. 3-12, 1989.

[34] F. J. Vecchio and M. P. Collins, "The modified compression field theory for reinforced concrete elements subjected to shear," ACI Structural Journal, vol. 83, no. 2, pp. 219-231, 1986.

[35] F. J. Vecchio and M. P. Collins, "Predicting the response of reinforced concrete beams subjected to shear using the modified compression field theory," ACI Structural Journal, vol. 85, no. 3, pp. 258-268, 1988.

[36] D. H. Lee and A. S. Elnashai, "Seismic analysis of RC bridge columns with flexure-shear interaction," Journal of Structural Engineering, vol. 127, no. 5, pp. 546-553, 2001.

[37] G. Ozcebe and M. Saatcioglu, "Hysteretic shear model for reinforced concrete members," Journal of Structural Engineering, vol. 115, no. 1, pp. 132-148, 1989.

[38] D. H. Lee, Inelastic seismic analysis and behaviour of $R C$ bridges, Ph.D. thesis, Imperial College London, London, UK, 1999.

[39] D. H. Lee and A. S. Elnashai, "Inelastic seismic analysis of RC bridge piers including flexure-shear-axial interaction," Structural Engineering and Mechanics, vol. 13, no. 3, pp. 241-260, 2002.

[40] B. M. Broderick and A. S. Elnashai, "Analysis of the failure of interstate 10 freeway ramp during the Northridge earthquake of 17 January 1994," Earthquake Engineering \& Structural Dynamics, vol. 24, no. 2, pp. 189-208, 1995.

[41] B. M. Broderick, A. S. Elnashai, N. N. Ambraseys, J. M. Barr, R. G. Goodfellow, and E. M. Higazy, "The Northridge
(California) earthquake of 17 January 1994: observations, strong motion and correlative response analyses," ESEE research report No. 94/4, Imperial College, London, UK, 1994.

[42] ACI Committee 318, "Building code requirements for structural concrete (ACI 318M-14) and commentary (ACI 318RM-14)," American Concrete Institute, MI, USA, 2015.

[43] M. J. N. Priestley and G. Benzoni, "Seismic performance of circular columns with low longitudinal reinforcement ratios," ACI Structural Journal, vol. 93, no. 4, pp. 474-485, 1996. 